\title{
A depth versus diameter scaling relationship for the best-preserved melt-bearing complex craters on Mars
}

${ }^{1}$ Livio L. Tornabene, ${ }^{2}$ Wesley A. Watters, ${ }^{1,3}$ Gordon R. Osinski, ${ }^{4}$ Joseph M. Boyce,

${ }^{5}$ Tanya N. Harrison, ${ }^{1}$ Victor Ling, ${ }^{6}$ Alfred S. McEwen

${ }^{1}$ Centre for Planetary Science and Exploration/Department of Earth Sciences, University

of Western Ontario, London, ON N6A 5B7, Canada

${ }^{2}$ Whitin Observatory, Department of Astronomy, Wellesley College, 106 Central St.,

Wellesley, MA 02481, USA

${ }^{3}$ Department of Physics and Astronomy, University of Western Ontario, London, ON N6A

3K7, Canada

${ }^{4}$ Hawaii Institute of Geophysics and Planetology, University of Hawai'i, Honolulu, HI 96822, USA5

${ }^{5}$ NewSpace Initiative, Arizona State University, P.O. Box 876004, Tempe, AZ 85287

${ }^{6}$ Lunar and Planetary Laboratory, University of Arizona, Tucson, AZ 85721, USA

*Corresponding author e-mail: 1tornabe@uwo.ca 


\begin{abstract}
We use topographic data to show that impact craters with pitted floor deposits are among the deepest on Mars. This is consistent with the interpretation of pitted materials as primary crater-fill impactite deposits emplaced during crater formation. Our database consists of 224 pitted material craters ranging in size from $\sim 1$ to $150 \mathrm{~km}$ in diameter. Our measurements are based on topographic data from the Mars Orbiter Laser Altimeter (MOLA) and the High-Resolution Stereo Camera (HRSC). We have used these craters to measure the relationship between crater diameter and the initial post-formation depth. Depth was measured as maximum rim-to-floor depth, $\left(d_{r}\right)$, but we also report the depth measured using other definitions. The database was down-selected by refining or removing elevation measurements from "problematic" craters affected by processes and conditions that influenced their $d_{r} / D$, such as pre-impact slopes/topography and later overprinting craters. We report a maximum (deepest) and mean scaling relationship of $d_{r}=$ $(0.347 \pm 0.021) D^{0.537 \pm 0.017}$ and $d_{r}=(0.323 \pm 0.017) D^{0.538 \pm 0.016}$, respectively. Our results suggest that significant variations between previously-reported MOLA-based $d_{r} v s . D$ relationships may result from the inclusion of craters that: 1) are influenced by atypical processes (e.g., highly oblique impact), 2) are significantly degraded, 3) reside within highstrength regions, and 4) are transitional (partially collapsed). By taking such issues into consideration and only measuring craters with primary floor materials, we present the best estimate to date of a MOLA-based relationship of $d_{r} v s$. $D$ for the least-degraded complex craters on Mars. This can be applied to crater degradation studies and provides a useful constraint for models of complex crater formation.
\end{abstract}




\section{Introduction}

The morphology and morphometry of impact craters provides useful information regarding the impact process, the physical properties of planetary surfaces (e.g., composition, volatile-content, structure, etc.), and subsequent erosional and depositional processes over time. One of the most useful measurements in this regard is the ratio of postformation rim-to-floor depth and diameter $\left(d_{r} / D\right)$. Specifically, knowing the $d_{r} v s . D$ function for Martian craters is essential for constraining local and regional degradation rates, and for calibrating both crater degradation and impact cratering hydrocode models for Mars. Toward this end, the majority of recent studies have relied the analysis of very large sample populations of impact craters (1,000s to 10,000s), where the deepest craters in these sample populations are assumed to be the best-preserved (e.g., Garvin et al., 2003; Boyce and Garbeil, 2007; Robbins and Hynek, 2012a; 2013). While this is generally true, there are exceptions; indeed, $d_{r}$ is influenced by all the stages of the impact process (e.g., Melosh, 1989) and by impact parameters such as the nature of the projectile, impact velocity, impact angle, melt volume, target lithology, and both target slope and topography.

The effects of target slope and topography on $d_{r} v s . D$ scaling has become especially apparent with the increase in meter-scale high-resolution image coverage over the last decade. As such, it has become vitally important to visually inspect craters carefully with high-resolution images, to not only assess the elevation data coverage over them, but to identify craters with morphologies that have been influenced by pre-impact target conditions or additional processes. With this in mind, the recognition of the primary craterfill deposits is arguably the most important criteria to identify the best-preserved craters and assess the effects of various impact parameters on $d_{r}$. This is especially important when 
the goal of a study is to identify a sample population that can be used to determine a globally representative post-impact formation $d_{r}$ vs. $D$ scaling (i.e., the least modified depth).

Until recently, it was hypothesized that the primary crater fill (i.e., impact melt-bearing deposits) on Mars should be morphologically similar to lunar impact melt-bearing deposits. Because such "lunar-like" deposits have not been commonly observed on Mars (MouginisMark and Garbeil, 2007), they were initially deemed extremely rare, buried, or eroded beyond recognition. However, Tornabene et al. (2012) has shown that impact melt-bearing crater-fill deposits are not as rare as previously suggested, and that the deposits referred to as "crater-related pitted materials" (see Fig. 1) correspond to "impact melt sheets" observed on the Moon for decades (e.g., Grieve et al., 1977; Hawke and Head, 1977). The occurrence and morphology of these pitted materials are consistent with them being volatile-rich impact melt-bearing deposits that are perhaps similar to impact melt-bearing breccias documented in terrestrial craters, commonly referred to as "suevite" (McEwen et al., 2007a; Tornabene et al., 2007; 2012; Boyce et al., 2012; Denevi et al., 2012; MouginisMark and Boyce, 2012; Sizemore et al., 2017).

Until now, the recognition of the primary crater-fill deposits has not been considered 3 as a criterion for the identification and analysis of the best-preserved craters on Mars (e.g., Garvin et al., 2003; Stewart and Valiant, 2006; Boyce and Garbeil., 2007; Whitehead et al., 2010; Robbins and Hynek, 2012a; 2013). One very recent exception is Mouginis-Mark et al. (2017), however, a close inspection of their sample population reveals that it is comprised of a mixture of craters with and without pitted materials: only $16 \%$ of their craters have these distinctive deposits. 
Two-hundred and twenty-four Martian craters containing pitted materials are currently recognized, ranging from $\sim 1$ to $150 \mathrm{~km}$ in diameter, and are randomly distributed over the mid- to lower-latitudes (between $\sim 60^{\circ} \mathrm{N}$ and $\mathrm{S}$ ) (Tornabene et al., 2012). This study focuses on these craters to determine whether they are indeed among the deepest craters on Mars, as suggested in Tornabene et al. (2012), and then to use their depths and diameters to derive a robust $d_{r} v s$. $D$ scaling relationship for the best-preserved craters on Mars. Herein, we make measurements based on the known pitted material bearing craters using elevation data provided by the Mars Orbiter Laser Altimeter (MOLA) and the High-Resolution Stereo Camera (HRSC).

\section{Background and Methods}

Past studies addressing crater $d_{r} v s . D$ scaling have relied on both a variety of datasets and techniques, including photoclinometry, radar, stereo-photogrammetry, and laser altimetry. While stereo image-derived elevation data has recently been suggested to provide the most accurate measure of crater morphometric properties (e.g., Mouginis-Mark et al. 2017), the production of elevation data via this method is computationally-intensive and time-consuming. The use of high-resolution stereo elevation data is also significantly hindered by its limited global coverage. In many cases, a single observation is not large enough to cover a single crater completely, especially at large diameters (e.g., pitted material-bearing craters in this study up to $\sim 100 \mathrm{~km}$ in $D$ ). The lack of coverage poses some difficulty with not only the derivation of regional and global crater $d_{r} v s$. $D$ scaling relationships, but also with respect to the application to specific regions, as any relationship based on limited coverage may not be representative (e.g., studies of crater degradation in specific regions). Measuring crater $d_{r}$ via photoclinometric methods (e.g., Pike, 1980a; Pike 
and Davis, 1984) is still useful in cases where MOLA is insufficient and stereo-derived elevation is not available; however, the requirements for accurate measurements through shadow-based and photoclinometric methods (e.g., favorable lighting geometry, uniform albedo and knowledge of the shape of the crater floor) are not consistently present for many craters on Mars, including the ones that are the focus of this study.

Because all of the datasets and techniques mentioned above have their own limitations, making comparisons between different studies is challenging. In this study, we have mainly relied on the MOLA dataset, because it has the largest global coverage and remains the most widely-used data set for measuring complex crater morphometry on Mars. This is also important with respect to the relevance and applicability of the scaling relationships that are derived herein to other studies, as these equations and the MOLA dataset can be applied to degraded craters at local and regional scales to place constraints on landscape evolution and past climate conditions on Mars. Despite limitations in coverage, we also supplement our MOLA-based results with measurements for the same craters using HRSC stereo-derived Digital Terrain Models (DTMs) to gauge differences between these datasets.

\subsection{Datasets and Methods}

The original global database of 205 craters with associated pitted materials defined by (Tornabene et al., 2012) was used as our starting sample population, plus an additional 19 craters discovered to possess pitted materials since 2012 for a total of 224 craters (see Table $\mathrm{S} 1$ and associated readme file for more information). Measurements of crater depths were accomplished using both the MOLA Merged Experimental Gridded Data Record (MEGDR) DTM and the individual laser shots of the Precision Experimental Data Record 
(PEDR) (Smith et al., 2001), in addition to DTMs derived from stereo images provided by HRSC (Neukum et al., 2004; Jaumann et al., 2007).

The MOLA data were first visualized within the Java Mission And Remote Sensing (JMARS) software package (Christensen et al., 2009). MOLA PEDR data were individually compiled as a shapefile for each crater using the Planetary Data System (PDS) Geosciences Node's web-based MOLA PEDR query applet (see http://ode.rsl.wustl.edu/mars/datapointsearch.aspx). Each PEDR shapefile overlapping a specific crater was loaded into JMARS and the PEDR shots were carefully examined in relation to high-resolution visible images and stereo-derived anaglyphs (see Fig. S1) from the Context Imager (CTX; $\sim 6 \mathrm{~m} / \mathrm{pixel})$ and HiRISE ( $\sim 30 \mathrm{~cm} /$ pixel) (Malin et al., 2007; McEwen et al., 2007b).

In this study, the crater MOLA PEDR-derived $d_{r}$ was generally measured as the difference in elevation between the maximum rim elevation and the lowest elevation of the crater floor (Fig. 1). Taking a maximum value rather than an average, as has been done using relatively complex methods by other workers (e.g., Stewart and Valiant, 2006; Boyce and Garbeil, 2007; Whitehead et al., 2010; Robbins and Hynek, 2012a; 2013; Robbins et al., 2017), provides a rapid, easy, and consistent method for measuring crater depth, so long as the following are taken into consideration: 1) the measurement uncertainty, 2) the natural variation in crater rims/floors, and most importantly, 3) a detailed visual inspection of the crater, in order to address various complicating factors that may otherwise result in a depth that is inaccurate. For completeness, however, we also report depths and diameters of the craters in our study as measured by Robbins and Hynek (2012a), who used the average rim height and average crater floor elevation (see Section 3.1)." 


\section{[Figure 1]}

All crater diameters were initially measured using a best-fit circle to a manual trace of the crater rim using the most complete and highest resolution dataset available for a given crater (most often the $100 \mathrm{~m}$ THEMIS daytime IR brightness temperature global mosaic (Christensen et al., 2004; Edwards et al., 2011).

Previous studies have documented the difficulties inherent to using $~ 160$-m shot-size with 300-m along-track spacing of the MOLA elevation data to document crater morphometric parameters, especially for smaller craters and in the equatorial regions where track spacing can be up to several km (Smith et al., 2001; Stewart and Valiant, 2006; Boyce and Garbeil, 2007; Robbins and Hynek, 2012a; 2013; Mouginis-Mark et al., 2017). All craters were carefully inspected to assess the PEDR coverage of the crater rim and floor, and to determine if a crater is "problematic" in some way (see definitions in Section 2.2). This was done to ensure that PEDR coverage was sufficient to give an accurate estimate of the maximum crater depth, and so that only depths not influenced by a variety of complicating pre- syn- and post-impact factors would be used for our final power-law regression analysis. All craters were visualized with their PEDR coverage atop CTX or HiRISE images co-registered with the MOLA MEGDR colorized elevation and shaded relief map. Craters with the poorest MOLA PEDR coverage (e.g., low shot counts or shots that largely miss the rim and/or the deepest parts of the crater floor) were discarded from our analysis (e.g., see Figs. 2b and 2e in Mouginis-Mark et al., 2017). HiRISE anaglyphs, when available, were particularly useful to visually determine whether the highest rim height or the deepest portions of the crater floor were sampled or missed by the MOLA PEDR shots. In some cases, this step allowed us to include craters where MOLA shot- 
coverage was poor, but nevertheless acceptable because the shots happened to cover the highest elevations in the crater rim and the lowest portions of crater floor (e.g., Fig. S1).

The maximum rim-to-floor depth $\left(d_{r}\right)$ was initially measured as a simple difference between the highest elevation measured on the rim to the lowest elevation measured on the crater floor. The visual inspection of all craters allowed us to improve on this by assessing whether elevations of complicating and anomalous features in "problematic" craters could be avoided. For example, elevations sampled from the floor of an overprinting crater within the crater-fill deposits, or rim elevations influenced by pre-impact topography (e.g., see Figs. 8 and 9 in McCoy et al., 2008), were avoided as these would provide a depth estimate that was not characteristic of the cratering process under normal target conditions (see Section 2.2). Throughout the remainder of this study, the process of inspecting imagery in order to discard "problematic" craters or to refine the measurements by avoiding topographic anomalies, is simply called "refinement". These "refined" measurements are distinct from our initial set of measurements (all craters and without regard to topographic anomalies), which are simply called the "unrefined" depth estimates.

For comparison with our MOLA-derived measurements, we measured $d_{r}$ and $D$ for pitted material-bearing craters using a semi-automated algorithm developed by Watters et al. (2015) from HRSC stereo-derived DTMs ( 50 - 250 meters per post) where available. HRSC DTMs were chosen as they provide far more coverage of pitted material-bearing craters than what is currently available from other stereo image-derived DTMs (i.e., CTX and HiRISE) (see Mouginis-Mark et al., 2017). Two HRSC DTM-based measurements of crater depth were made for comparison with the MOLA results. The first estimate is the overall maximum rim-to-floor depth $\left(d_{\max } / D\right)$, where $d_{\max }$ is measured as the maximum rim 
elevation to the minimum floor elevation, excluding elevations from overprinting craters and central pits. The second estimate is $d_{a v g} / D$, measured from a minimum floor depth (again excluding floor craters and central pits) to the average rim height. The rim in the HRSC DTM is identified via a script that finds the tallest ridge circumferential to the crater by connecting elevation maxima along evenly-spaced radial elevation profiles. The algorithm assembles a continuous rim from candidate ridges by minimizing radial discontinuities. In approximately one-fifth of the cases, manual intervention was required to remedy instances where the automated rim-finder could not accurately trace the crater rim. This was due to the presence of both interior and exterior terraces in complex craters, which can make it difficult to uniquely identify the rim crest, causing a radial discontinuity or "jump" from the actual rim towards one of these terraces. After the rim is identified and verified, a plane is fit to this rim crest and this plane is subtracted from the DTM to remove the regional topographic trend. As such, the average rim elevation is set to zero, and the crater depth can be read from the minimum elevation value. We note that the number of measurements to obtain an average rim height in this manner is determined by the DTM resolution. As an example, a $100-\mathrm{km}$ crater measured with a 250 meter per post DTM would consist of approximately 1250 measurements. For more on these methods, see Watters et al. (2015).

\subsection{Sources of variation and error}

Accurate identification of the crater rim depends on image resolution and the ability of an observer to resolve the topographic rim, which generally requires $\sim 3$ pixels (e.g., $\sim 300$ $\mathrm{m}$ for THEMIS). This is usually a minor source of error when measuring the crater $D$, with variation from user-to-user being generally less than $\sim 10 \%$ on average between analysts (e.g., Robbins and Hynek, 2013). By comparing the crater diameter measurements for the 
sample population used in this study to the diameter measurements for the same craters catalogued in the Robbins and Hynek (2012) database, we find that our diameter estimates are within $\sim 2 \%$ on average, with a max difference of $\sim 11 \%$. Comparing the measured diameters from the Tornabene et al. (2012) pitted material database with automated measurements of diameters based on Watters et al. (2015), we get a comparable result with a difference of $\sim 3 \%$ on average, and a maximum difference of $15 \%$. Furthermore, the craters used in our final $d_{r} v s . D$ analysis exhibit little variation from a perfect circle. The Watters et al. (2015) automated analysis using the HRSC DTMs supports this, showing that a best-fit circle only deviates from the actual rim by $\sim 3.5 \% \pm 1.5 \%$ of total diameter, and ranges from $\sim 1.7 \%$ to $6.6 \%$ (e.g., a crater we report as $20 \mathrm{~km}$ in diameter may represent a crater whose diameter varies between $\sim 18.6$ and $21.4 \mathrm{~km})$.

The accurate measure of the natural variation in elevations along a crater rim is one of the largest sources of uncertainty in estimates of crater rim-to-floor depth (see Boyce et al., 2005; Stewart and Valiant, 2006; Kalynn et al., 2013). Based on the analysis of Stewart and Valiant (2006), the error on the rim height based on MOLA measurement of variation in rim elevation is $\sim 10-20 \%$. When compared to the depth of a crater, the rim height makes up $\sim 15-20 \%$ of the total depth for simple craters and as much as $\sim 50 \%$ for complex craters (e.g., Pike, 1980a; 1980b; Stewart and Valiant, 2006). That is, the smallest simple craters have a rim that is a smaller proportion of the crater depth, because there is minimal rim collapse, while large craters exhibit more extensive gravitationally-driven collapse, so that the rim height is a larger proportion of the crater depth ( $50 \%)$. By combining these above factors, the maximum variation of crater depth attributed to the rim height is at most only $\sim 10 \%$, which is consistent with previous estimates. 


\section{[Figure 2]}

Central pits in complex craters may have elevations below the crater floor (e.g., Barlow, 2006) and therefore provide a maximum depth that is larger than what would be expected for a crater of a given diameter, on average. In the case of our "refined" measurements avoid central pits by measuring the lowest elevation of the crater-fill deposits outside of the central pit (e.g., Figs. 2a and 3). Similarly, and as mentioned in an earlier example, elevations originating from overprinting craters were avoided (e.g., Fig. 2a). Additionally, highly elliptical craters were discarded from our analysis because they exhibit highly asymmetric diameters (major/minor axis length ratio $>1.1$ ), have asymmetric rim elevations and significant floor slopes downrange, and have shallower cavities (e.g., Pierazzo and Melosh, 2000).

Previous studies have shown that pre-existing slopes and topography can significantly affect the elevation variations of the crater rim and floor (e.g., Boyce et al., 2005; Stewart and Valiant, 2006; Boyce and Garbeil, 2007; Kalynn et al., 2013) and also result in nonrepresentative elevations for depth vs. diameter scaling, which is also discussed in Section 2.1. Importantly, the features associated with such craters are often not readily recognized in elevation maps alone (Fig. 3), but are best recognized when cross-referencing DTMs with visible and thermal infrared images to provide the additional context to make this assessment. Examples of craters that were "refined" and where elevation measurements were carefully chosen to avoid topographic anomalies are shown here; when this was not possible, the crater was completely discarded (e.g., Figs. 2b and 2c; also c.f., Fig. 2b with its $d_{r}$ vs. $D$ plotted in Fig. 4).

\section{[Figure 3]}


A previous approach used to rapidly filter-out "problematic" craters that occur in topographically complex terrains is to consider only craters formed into plains units (Boyce et al., 2005; Boyce and Garbeil, 2007; Stewart and Valiant, 2006). Here we include craters in heavily-cratered and topographically complex terrains because our sample population is much smaller than previous studies (i.e., 100s vs. 1000s) and the intention here is to use a sample population representing the least post-impact in-filled craters. However, because our sample population is smaller than previous studies, we are readily able to inspect all of our craters to determine if they exhibit any significant depth-modifying features and whether these features can be simply avoided when making measurements (see Fig. 3). We used colorized MOLA and THEMIS Day IR images, or other higher-resolution images (e.g., CTX and HiRISE), as needed and based on availability. This is a crucial step for assessing craters for use in a study of $d_{r} v s$. $D$, because it allows for the simultaneous assessment of various depth-enhancing effects and morphologic characteristics that may otherwise be difficult, if not impossible, to assess in the MOLA MEGDR dataset alone (c.f., Figs. 3a-d). Where it was impossible to avoid problematic features when measuring elevations to estimate $d_{r}$, craters were flagged and excluded when computing our powerlaw fit for $d_{r} v s . D$ (e.g., Fig. 2b). (Figs. 2a and 3d), but in many cases, the elevation effects were too severe and craters had to be discarded from our final analysis (e.g., Fig. 2b).

Based on poor MOLA PEDR data-coverage, influence of pre-existing topography or post-impact modification effects as described above, 125 of the 224 craters were classified as "problematic". Seven additional craters were flagged at this stage. The largest crater in our sample population, Bakhuysen, was dropped from our analysis due to the poor statistics in our sample population in the 100 - to $150-\mathrm{km}$ diameter range (i.e., only two craters in our 
sample population are within this range). The other crater in this range, Hale Crater was already discarded due to its elliptical shape (approximately $\sim 125 \times 150 \mathrm{~km}$ ) and because it is also situated on a major regional topographic slope formed by the Argyre Basin. Six craters were flagged for careful treatment because they occur in the Utopia and Isidis region, which are interpreted to be "high-strength target regions" based having deeper complex craters and the largest simple craters on Mars (Boyce et al., 2006; Stewart and Valiant, 2006). In Section 4, we report power-law regressions that include as well as exclude "problematic" craters and the seven craters just mentioned.

\section{Results}

\subsection{MOLA and HRSC-derived depth/diameter measurements}

We were left with 92 craters following the refinement steps (D 2-100 km), which is less than half $(\sim 41 \%)$ of our starting sample population. The complete set of measurements, including unrefined measurements and results from "problematic" craters, are provided as a table in the online supplement for this paper (see Table S1).

Figure 4 shows a plot of unrefined measurements for all craters in our database with a diameter of $2 \mathrm{~km}$ and above, in addition to two of the publicly available crater databases used that include depth and diameter measurements (Boyce et al., 2005; Robbins and Hynek, 2012b). Figures $4 \mathrm{a}$ and $4 \mathrm{~b}$ show that pitted material-bearing craters are indeed among the deepest craters on Mars. In addition to our measurements of depth, which are based on the maximum rim-to-floor depth, we also plot the measurements by Robbins and Hynek (2012b) of the same 92 pitted-material craters (i.e., average rim elevation minus average floor elevation based on the global MOLA MEGDR DTM). We report the power- 
law regression fit to these measurements in Section 3.1.2. Although the Robbins and Hynek (2012b) measurements for the same pitted material-bearing craters from this study appear shallower, we find that $93.6 \%$ of the crater depths they reported are shallower than what is predicted by this relationship. Roughly $97 \%$ are shallower than the upper bound of the 1sigma confidence interval, consistent with the argument that pitted material-bearing craters are amongst the deepest craters on Mars. Based on these results, and the observations and interpretations in Tornabene et al. $(2007 ; 2012)$, the pitted materials remain consistent with the hypothesis that they represent the top-most surface of the primary crater-fill deposits.

\section{[Figure 4]}

Figure 5 shows there is good agreement between depth measurements from MOLA PEDR and HRSC DTMs for craters with $\mathrm{D} \geq 10 \mathrm{~km}$, while craters with $\mathrm{D}<10 \mathrm{~km}$ show a larger deviation. This is attributed to the increased difficulty of resolving smaller craters with the MOLA PEDR data, and is in agreement with the findings of Robbins and Hynek (2013). For craters with $\mathrm{D}<10 \mathrm{~km}$, the maximum crater depth from PEDR and HRSC measurements disagree by $8.5 \%$ on average. By contrast, for craters with a $D \geq 10 \mathrm{~km}$, the PEDR-derived maximum depths and HRSC-derived maximum depths are within $\pm 4.2 \%$ of a 1:1 relationship (solid-line in Fig. 5a). (Also for $D \geq 10 \mathrm{~km}$, the PEDR-derived maximum depths are $13.3 \pm 7.3 \%$ larger, on average, when compared with the average depth measured from the HRSC DTMs: i.e., average rim height to minimum floor depth; see Fig. 5b.)

Based on these results, our measurements of maximum crater depth for $D \geq 10 \mathrm{~km}$ using MOLA PEDR data have an uncertainty of roughly $\sim 4 \%$. Although it is always better to apply measurements and scaling laws based on the same dataset and similar methods, 
this small difference in our measurements suggests that MOLA PEDR and HRSC DTMs may serve to complement one another in future studies.

\section{[Figure 5]}

Furthermore, our HRSC analysis indicates that the total rim relief, on average, is $\sim 34.9 \% \pm 15.1 \%$ of the average depth for complex craters ranging between $\sim 12-100 \mathrm{~km}$ in diameter. The standard deviation of rim elevation is on average $\sim 7.7 \% \pm 3.8 \%$ of the average depth. Twice this number $(\sim 15 \%)$ is a useful measure of uncertainty of maximum rim-to-floor depth measurements, since any measurement based on above-average rim heights is likely to be within $15 \%$ of the actual maximum depth. This is useful since PEDR shots only represent a small subsample of all elevations on the rim of a crater, which is covered more fully by stereo-derived DTMs such as HRSC. Moreover, the variation in rim height is a much larger source of uncertainty than the error of individual MOLA spot measurements, which is $\sim 160 \mathrm{~m}$.

\subsubsection{Additional considerations before deriving $d_{r} / D$ scaling relationships}

\section{[Figure 6]}

Although we have measurements for craters spanning 2-100 km in diameter with 40 refined depth measurements for craters having $\mathrm{D}<12 \mathrm{~km}$, we do not present scaling relationship for simple craters in this study. There is an observable shift in the $d_{r} v s . D$ behavior of our sample population at $\sim 9 \mathrm{~km}$ in diameter (c.f., Fig. $4 \mathrm{~b}$ and 6 ) that marks the approximate transition from deep transitional craters to complex craters. At diameters smaller than this value, a visual inspection reveals that most of the craters have transitional crater morphologies rather than simple ones (Fig. 7). Transitional craters exhibit the hallmarks of being significantly influenced by gravitationally-induced collapse. As such, 
these craters have depths that are shallower than simple craters, but deeper than complex craters of the same diameter. Only 3 of our craters below $12 \mathrm{~km}$ in diameter have morphologies entirely consistent with simple craters (Fig. 7a).

\section{[Figure 7]}

The smallest and shallowest transitional crater in our sample population is the $\sim 4.1-\mathrm{km}$, well-preserved thermal rayed crater called Nayrn $\left(123.3^{\circ} \mathrm{E}, 14.9^{\circ} \mathrm{N}\right)$ (see Tornabene et al., 2006) (c.f., Figs. 6 and 7b). A close inspection of this crater reveals that the shallowing of the depth is not due to degradation effects (see Fig. 7b), but enhanced gravitational collapse leading to slumping and the formation of flat floors. Other craters in this size range show similar collapse features, such as the well-preserved $\sim 4.6-\mathrm{km}$ Istok Crater $\left(274.2^{\circ} \mathrm{E}\right.$, 45.1 ${ }^{\circ} \mathrm{S}$ ) (see Fig. 9 in Tornabene et al. (2012) and Johnsson et al. (2014) for more on Istok), and an $\sim 8.8-\mathrm{km}$ unnamed crater located at $43.13^{\circ} \mathrm{E}, 23.13^{\circ} \mathrm{S}$ in Noachis Terra (Figs. $7 \mathrm{c}$ and $7 d)$.

Previous studies have shown that transitional morphologies on Mars occur at a size as small as $\sim 3 \mathrm{~km}$ in diameter, and simple craters have been observed as large as $\sim 12 \mathrm{~km}$ in diameter (Pike, 1980b; Pike and Davis, 1984; Boyce et al., 2005, 2006; Stewart and Valiant, 2006; Boyce and Garbeil, 2007; Robbins and Hynek, 2012a). Our sample population is largely consistent with these previous results, with our transitional craters mostly falling between $\sim 3-9 \mathrm{~km}$ in diameter. Because simple crater morphologies have been previously observed up to $\sim 12 \mathrm{~km}$ ( 11.8 km; Boyce et al., 2005; Boyce and Garbeil, 2007), we remove all craters less than $12 \mathrm{~km}$ in diameter before deriving a depth vs. diameter scaling relationship for complex craters. 


\subsubsection{Complex crater $d_{r} v s$. $D$ scaling relationship for pitted material-bearing craters}

To derive a power-law regression for the deepest complex craters, a geometric binning technique similar the one used by Boyce and Garbeil (2007) and Robbins and Hynek (2012; 2013) was applied to the complex craters in our sample populations both before $(n=134)$ and after $(\mathrm{n}=51)$ the "refinement" steps (see below and Tables 1 and 2). We use 12 diameter bins that are evenly-spaced in log diameter (base 10). We provide power-law fits to the deepest craters in each bin, as well as all of the remaining complex craters in our sample populations (i.e., a mean relationship; see Fig. 6). We also provide fits to the 2 deepest and 3 deepest craters in each bin to observe the variation in fit parameters as additional craters are added. Note that all diameters and depths reported herein are in kilometers $(\mathrm{km})$.

In summary, the $d_{r} v s . D$ scaling relationships for complex craters with pitted materials (after refinement) and having $D \geq 12 \mathrm{~km}$ are as follows:

\section{Deepest Complex:}

$d_{r}=0.347( \pm 0.021) D^{0.537( \pm 0.017)}\left(\mathrm{n}=11 ; \mathrm{r}^{2}=0.991\right)$

\section{Mean Complex:}

$d_{r}=0.323( \pm 0.017) D^{0.538( \pm 0.016)}\left(\mathrm{n}=51 ; \mathrm{r}^{2}=0.960\right)$

If we perform a minimal refinement to our original sample population that only removes the most extreme outliers from the sample population (see Fig. 4a), the max and mean relationships are as follows: 


\section{Deepest Complex (BEFORE "refinement"):}

$d_{r}=0.473( \pm 0.062) D^{0.503( \pm 0.035)}\left(\mathrm{n}=11 ; \mathrm{r}^{2}=0.958\right)$

Mean Complex (BEFORE "refinement"):

$d_{r}=0.336( \pm 0.024) D^{0.541( \pm 0.021)}\left(\mathrm{n}=134 ; \mathrm{r}^{2}=0.839\right)$

Finally, we also provide here power-law fits to MOLA-based measurements originating from the Robbins and Hynek (2012b) database for the same craters in our refined sample population. While the Robbins and Hynek (2012b) database has entries for all the complex craters in our refined sample population $(\mathrm{n}=51)$, the Boyce et al. (2005) database unfortunately only has six craters that also appear our database, ranging from 12.7 to 26.2 $\mathrm{km}$ in diameter. Thus, we do not provide a power-law fit to these six craters due to poor coverage of the diameter range and poor statistics. The power-law fit to the Robbins and Hynek (2012b) measurements is given by:

\section{Mean Complex (Robbins and Hynek PM-overlaps):}

$d_{a}=0.272(+0.021) D^{0.517}\left(\mathrm{n}=51 ; \mathrm{r}^{2}=0.915\right)$

where $d_{a}$ is an average depth (average rim elevation to average floor elevation) based on the MOLA MEGDR DTM as opposed to our measurement of maximum rim-to-floor depth $\left(d_{r}\right)$ which is based exclusively on MOLA PEDR tracks. Finally, we note that $d_{r} / d_{a}=1.28$ \pm 0.09 , on average, for complex craters in our down-selected population. 


\section{Discussion}

\subsection{Comparisons of complex crater depth vs. diameter relationships}

Before delving into the comparisons of complex crater depth vs. diameter relationships, we summarize here how each of the previous MOLA-based studies made their measurements of crater depth, including which MOLA product was emphasized (i.e., PEDR - the individual shots/tracks vs. MEGDR - the gridded and interpolated global DTM). Garvin et al. (2003) used the individual shots of the PEDR dataset, specifically focusing on tracks that cross crater centers and their minima and maxima to calculate crater depth. Boyce et al. (2005), including Boyce et al. (2006) and Boyce and Garbeil (2007), primarily focused on the MEGDR dataset using the difference between average rim height and the lowest floor elevation to calculate crater depth. Stewart and Valiant (2006) used both the PEDR and the MEGDR for the rim and floor measurement, respectively. The rim height was derived from individual MOLA PEDR shots and the average cavity floor elevation was measured from the MEGDR dataset. Both Stepinski et al. (2009) and Whitehead et al. 2010 provide depth estimates based the MOLA MEGDR; Stepinski et al. (2009) based theirs on averages of the rim and crater floor from while Whitehead et al. 2010 based theirs on profiles. Robbins and Hynek (2012a) used the MEGDR and the same approach as Boyce et al. (2005), whereas Robbins and Hynek (2013) used PEDR elevations to estimate the rim-to-floor depth, as measured from the mean of above-average rim heights to the mean of the below-average floor depths.

\section{[TABLE 1]}

Tables 1 and 2 show the coefficients, exponents, formal errors, $\mathrm{r}^{2}$ values, and additional information regarding complex crater depth vs. diameter scaling relationships from this 
and previous studies based on MOLA. These are also graphically represented in two different ways to facilitate a visual comparison and discussion (Figs. 8 and 9). We report the scaling laws for "deepest craters" as well as "freshest craters". The "deepest craters" relationships are based on power-law fits to the deepest craters in logarithmic diameter bins. The "freshest craters" relationships are based on a definition in Boyce and Garbeil (2007), where the deepest $X \%$ of craters in each bin are averaged and a power law is fit to these values (e.g., in the case of Boyce and Garbeil (2007), X was 5\%). The implicit assumption by previous workers is that the deepest craters are the least infilled and are the best preserved. It is important to bear in mind, however, that such craters do not necessarily exhibit primary floor materials (pitted materials), and so these "freshest craters" scaling laws may include many craters with partially infilled cavities. Herein, the "freshest craters" relationships are synonymous with a mean relationship.

\section{[TABLE 2]}

Power-law fit-derived relationships for depth vs. diameter have the general form $d=$ $c \cdot D^{m}$, where $c$ is a coefficient that determines the amplitude of the function, and $m$ is an exponent that determines the slope in log-log space (i.e., rate of deepening/shallowing as a function of $D$ ). Values of $\mathrm{r}^{2}$ for the power-law regression analyses indicate the degree of correlation between the two variables $\log (d)$ and $\log (D)$, and is a measure of the departure from a linear log-log relationship (e.g., Boyce and Garbeil, 2007). In Section 4.2, we assess the variation of the parameters $c$ and $m$ between the variously reported MOLA-based scaling relationships (Fig. 9) and discuss how this variation may relate to degradation, target-strength effects or other factors (e.g., Stewart and Valiant, 2006; Boyce and Garbeil, 2007; Robbins and Hynek, 2012a, 2013). 


\section{[Figure 8]}

Excluding craters occurring within the high-strength target terrains of Utopia and Isidis Planitia from our sample population (see Section 4.2.3), we find good agreement between the "deepest craters" relationships in Figures 8a and 9. In Figure 9, the error bars on our reported fit parameter values represent two standard errors. (Unfortunately, few studies have supplied formal fit parameter uncertainties and so it is impossible for us to determine if our results agree to within the uncertainty of others' estimates.) This figure shows that all except one of the previous results reside within about two standard errors of our estimated fit parameters when high-strength targets are removed (small black star). The exception is the scaling law in Robbins and Hynek (2012a) for southern highlands craters, with a larger exponent and smaller coefficient. This scaling law shows good agreement only at large diameters (cyan line, Fig. 8a). The smaller coefficient and smaller depths at small diameters may be the result of strength effects (see Section 4.2.3), the difference in how depth was measured as an average $\left(d_{a}\right)$ rather than maximum $\left(d_{r}\right)$ and/or the use of the MOLA MEGDR DTM over the individual PEDR shots. For this reason, the Robbins and Hynek (2012a) results are better compared to our scaling law based on the average rim-tofloor depth ( $d_{a}$, red star in Fig. 9), as discussed further below.

\section{[Figure 9]}

Table 2 and Figures $8 \mathrm{~b}$ and 9 suggest that the "freshest craters" scaling relationships (power-law fits to the X\% deepest craters in each diameter bin; blue points in Fig. 9) are more different from each other than the "deepest craters" relationships (black points). In Figure 9 we compare these results to the power-law fits of our down-selected ("refined") population as a whole (as opposed to just the deepest craters in each diameter bin, as 
previously discussed). The blue stars represent the fit parameters of maximum rim-tofloor depth $d_{r}$ versus diameter with the Utopia and Isidis craters included (large blue star) and excluded (small blue star). As mentioned, the red star represents the fit parameters for the average rim-to-floor depth $\left(d_{a}\right)$, as measured in Robbins and Hynek (2012b), for all of the down-selected complex craters in our study $(\mathrm{n}=51, \mathrm{D} \geq 12 \mathrm{~km})$. As noted earlier, $d_{r} / d_{a}=1.28 \pm 0.09$ on average for complex craters in our down-selected population.

Whether craters in Utopia and Isidis are included or not, the exponents of these "freshest craters" relationships from other studies agree to within the $2 \sigma$ uncertainty of one of our results (red or blue stars), with several exceptions: the scaling laws measured for well-preserved complex craters in Mouginis-Mark (2017) as well as complex craters in Lunae Planum, Isidis Planitia, and Utopia Planitia in Stewart and Valiant (2006) (N.B. the Utopia craters are not plotted in Fig. 9: $c=0.738, m=0.29$ ).

In summary, most previous work has found the exponent of the depth vs. diameter scaling law for deep and well-preserved craters to reside between $0.51 \leq m \leq 0.54$. Estimates of the coefficient vary far more widely, with most studies finding $0.24 \leq c \leq$ 0.38 . With the exception of our "deepest craters" relationship when including the Utopia and Isidis Planitia craters (see next section), we find $0.51 \leq m \leq 0.54$. Our estimates for the coefficient are in the range $0.32 \leq c \leq 0.35$ when using the maximum rim-to-floor depth $\left(d_{r}\right)$. Using the average depth $\left(d_{a}\right)$ based on the MOLA MEGDR DTM lowers this to $c=$ $0.272 \pm 0.021$. The differences between fit parameters measured for complex craters on Mars may have several explanations, including: (a) differences in measurement methods; (b) differences in the definition of rim-to-floor crater depth; (c) the types of craters included in a sample population (especially degraded and/or "problematic" craters); and (d) the 
minimum diameter for which the scaling law is derived (e.g., $D \geq 12 \mathrm{~km})$. This is explored and discussed further in the next section.

\subsection{Sources of variation in reported complex crater depth vs. diameter scaling relationships}

In the following sections, we consider the various depth-modifying effects that could cause variations between MOLA-derived complex crater depth vs. diameter scaling relationships from this and previous studies. This assessment is facilitated by the analysis of the pitted material-bearing craters because these craters provide an observable criterion to ensure that the initial post-impact formation depth of these craters can be measured; thereby, a sample population of these craters essentially holds preservation state more or less constant over the entire diameter range. No other preservation criteria previously reported for Mars provides as much assurance that craters have experienced minimal to no infilling. In particular, we consider the influence of avoiding anomalous topographic features when measuring maximum rim-to-floor depth, omitting "problematic" craters, using "deepest craters" vs. "freshest craters" relationships, and including craters from highstrength regions. We also briefly consider the influence of different surface gravity.

\subsubsection{Variations caused by "problematic" craters}

Although the best-preserved craters are indeed among the deepest craters in a given sample population, we find that many of the deepest craters, upon closer inspection with available high-resolution images, are "problematic". As a reminder, our definition of "problematic" craters is: craters that are poorly resolved by MOLA, or have "anomalous" maximum depth due to extreme floor or rim elevation variations resulting from unusual processes or conditions, such as pre-impact topography, overprinting or neighboring 
craters, or central pits. This does not include degraded craters or craters in high- or lowstrength terrains as these are treated separately in Section 4.2.3.

The positive effects of discarding "problematic" craters and avoiding anomalous features when measuring maximum rim-to-floor depth are most clear by comparing Figures $4 \mathrm{a}$ and $4 \mathrm{~b}$. We find a marked reduction in the variation and spread of $d_{r} v s . D$ measurements (Figs. 4a and 4b) and concomitant improvement in the correlation as evidenced by higher $\mathrm{r}^{2}$ ( 14\% increase from 0.839 to 0.960 for the whole down-selected ("refined") population). The "deepest craters" show an increase in $\mathrm{r}^{2}$ of $\sim 3.5 \%$ from 0.958 to 0.991 . Also note that the exponent for both the "deepest craters" and mean scaling relationships for this study converge to a similar value ( 0.54; c.f., Tables 1 and 2 , Fig. 9) once "problematic" craters are properly addressed. Overall, the effect on the magnitude of fit parameters was to decrease depths at small diameters, lowering the coefficient and increasing the exponent of the scaling relationships; this would be represented as a shift toward the lower-right corner of Figure 9. This was unsurprisingly most pronounced for the "deepest craters" scaling relationship, since some of these craters have unusually large depths.

\subsubsection{Variations from degradation and infilling}

Boyce and Garbeil (2007) suggested that an observed systematic decrease in the coefficient from their "deepest craters" to "freshest craters" scaling relationships may be explained by the progressive degradation and infilling of craters. Starting with the sample population for their "deepest craters" relationship, they added the next deepest crater per bin incrementally while noting changes to the power-law fit parameters until there were 4 craters in each diameter bin. The progression from their "deepest craters" to their "freshest craters" relationship amounted to a decrease of $\sim 17.3 \%$ in the coefficient and comparatively little variation $(\sim 1.5 \%)$ in the exponent. This behavior appears to be 
suggestive of what is expected for infilling/degradation or "evolving craters in the same population" as described by Boyce and Garbeil (2007). The change from our "deepest craters" to mean relationship shows a similar trend in the coefficients and exponents (c.f., Tables 1 and 2, Fig. 9), with a $\sim 6.9 \%$ decrease in the coefficient, and $\sim 1.8 \%$ change in the exponent. The changes observed from both studies correspond to a mostly downward shift in Figure 9.

Nonetheless, the magnitude of the decrease in our scaling relationship coefficient cannot be explained by infilling/degradation alone. As a test, we used what is known about pit morphometry from Tornabene et al. (2012) to estimate how much infilling would be required to completely obscure the pits that occur within the pitted materials. Pit depth scales with pit diameter and pit diameter scales with crater diameter (Tornabene et al., 2012). Based on previously-derived scaling relationships, a moderately-sized complex crater $\sim 40 \mathrm{~km}$ in diameter would have a maximum pit diameter of $\sim 400 \mathrm{~m}$. A pit of this size would require $\sim 40$ - $\mathrm{m}$ thick deposit to obscure it along with the majority of the smaller pits on the crater floor. Adding a 40-m thick deposit to the estimated depth for a crater of this size amounts to less than a 3\% change in its depth, leaving another $\sim 4 \%$ to account for between our "deepest craters" and mean depth estimates. Because all the craters in this study have at least some surfaces comprising discernible crater-related pitted materials, we conclude that post-impact burial can only account for a small portion of the variation in $d_{r}$ between the "deepest craters" and mean relationships. Therefore, more than 50\% of this difference must arise from effects other than infilling and degradation of the craters, such as intrinsic variation in the cratering process or target strength effects. 
In considering other reported MOLA-based complex crater scaling relationships, it may be possible to account for the larger differences between the "deepest craters" and "freshest craters" relationships via the inclusion of more infilled craters in the sample populations used to determine the so-called "freshest craters" relationships. Indeed, the Boyce and Garbeil (2007) and Robbins and Hynek (2012a) "freshest craters" relationships provide estimates that are shallower than their reported "deepest craters" relationships by $\sim 21 \%$ and $\sim 47 \%$, respectively. A survey of 50 craters randomly chosen from among the deepest craters in the Robbins and Hynek (2012b) database and 50 from the Boyce and Garbeil (2007) database reveals that only some have pitted materials. Even when considering that not all primary crater-fill deposits are pitted (see Tornabene et al., 2012, and MouginisMark, 2015), the results from our survey of these databases reveal significant variations in the fraction of craters with pitted materials and that these constitute only a small fraction of all the "deepest" craters ( 14\% in Robbins and Hynek (2012b) and 26\% in Boyce and Garbeil (2007)).

In summary, our results suggest that a large number of infilled craters may have been included in other studies that report "freshest craters" scaling relationships, since the reported variation in crater depth significantly exceeds what we find for a sample population with exposed primary crater floor deposits (pitted materials), as well as the shallowing expected from burying the largest pits. Visual inspection of the supposedly "freshest craters" in two prior studies has confirmed this suggestion.

4.2.3. Variations due to target strength and the inclusion of "transitional" craters

Previous studies have examined the dependence of depth vs. diameter on variations in target strength (e.g., Pike 1980a, 1980b; Stewart and Valiant 2006; Boyce et al., 2006; 
Robbins and Hynek 2012a) as well as the range of diameters over which scaling relationships are fit. Several previous studies used 6 or $7 \mathrm{~km}$ as the lower-bound diameter when fitting their complex crater scaling relationships (see Tables 1 and 2) (i.e., Garvin et al., 2003; Stewart and Valiant, 2006; Whitehead et al., 2010; Robbins and Hynek, 2012a; 2013). By incrementally including additional craters below the $12-\mathrm{km}$ cut-off diameter, we have observed the effects of including transitional craters on our power-law fit parameters. This was accomplished by adding additional geometric diameter bins from 12 $\mathrm{km}$ down to $6 \mathrm{~km}$ and re-computing a power-law fit after each additional bin was added. These new "deepest craters" scaling relationships show an increasing progression in the coefficient from $0.347,0.405,0.429$ to 0.436 , and a decreasing progression in the exponents from $0.535,0.495,0.479$ to 0.475 . Smaller changes with the same trend are observed for our mean scaling relationship (fit to all refined measurements), from 0.380 to 0.388 for the coefficient and from 0.494 to 0.488 for the exponent. In general, the inclusion of transitional craters at smaller diameters causes depth vs. diameter trends to shift upwards at smaller diameters (i.e., an increase in the coefficient) and to exhibit a shallower slope in $\log$-log space at higher diameters (i.e., a decrease in the exponent). These changes amount to an observable systematic shift toward the upper left of the graph represented in Figure 9.

Not surprisingly, we see a similar shift in Figure 9 when we include the five pitted material-bearing complex craters from Southern Utopia Planitia and Isidis Planitia that were set aside earlier in our analysis. Previous studies show that these regions have the largest simple craters on Mars, which significantly exceed the average transition diameter, and exhibit anomalously deep cavities when compared to craters that occur outside of these 
regions (Boyce et al., 2006; Stewart and Valiant, 2006). Interestingly, these five complex craters cause a shift in our fit parameters despite having diameters larger than the $12-\mathrm{km}$ cut-off (i.e., $\sim 15-50 \mathrm{~km}$ in diameter) and have morphologies that are generally more consistent with complex craters. Indeed, their measured depths are $\sim 11-19 \%$ deeper than estimates based on our "deepest craters" and mean relationships (also refer to Fig. 8b). The observation of uncommonly deep complex craters has been reported from the results of recent models (e.g., Senft and Stewart, 2008; 2011), which suggest that a relatively high target strength will still have some influence on the final shape of some complex craters by producing relatively tall rims and, thereby, greater rim-to-floor depths. In addition to Utopia and Isidis, Chryse and Acidalia have also been suggested as high-strength target areas by previous workers (Robbins and Hynek, 2012a). All these regions represent lowlands or, in most cases, ancient basins that were extensively filled by volcanic deposits during periods of active volcanism on Mars. More recently, a study by Bandfield et al. (2013) identified high-strength targets based on their combined morphologic and thermophysical characteristics. They concluded that the majority of the most ancient terrains on Mars are weaker and consistent with poorly consolidated fine-particulate materials that may have a volcaniclastic origin (or alternatively, an impactoclastic origin), while younger stronger surfaces are consistent with more coherent bedrock originating from effusive volcanic activity.

As a final test to ascertain if there is any target strength dependence greatly influencing our refined sample population (including the 5 Isidis/Utopia complex craters; $n=56$ ), we performed a series of statistical tests to assess if the population tends to exhibit deeper cavities in stronger targets. We first classified the mapped geologic units in which our 
complex craters reside as "strong" or "weak", based on Tanaka et al. (2014). We interpret as "strong" targets the units dominated by lava plains and flows (i.e., Amazonian \& Hesperian volcanic [AHv], early Hesperian volcanic, [eHv], late Hesperian volcanic [lHv], late Amazonian volcanic [1Av] \& volcanic field [1Avf]; craters residing in the Amazonian \& Hesperian impact unit [AHi] were identified with the neighboring unit that shares its longest border). Craters forming in all other geologic units were designated as "weak" (i.e., heavily-cratered terrains).

With the exception of the estimates for specific regions detailed in the Caudill et al. (2012) and Quantin et al. (2012) studies, the maximum thickness for many of these lava fields and flows are largely unknown. We have assumed that these units are thick enough to behave as strong targets for all of the craters that formed in them.

We next applied the Kolmogorov-Smirnov (KS) and Anderson-Darling (AD) statistical tests (Kolmogorov, 1933; Smirnov, 1939; Anderson and Darling, 1954) to compare the distribution of crater depths for each strength category. Figure 10 shows cumulative distribution functions (CDFs, also known as "cumulative frequency" plots) for $d_{r} / D^{m}$ (N.B., since $d_{r}=c D^{m}$, we compute $d_{r} / D^{m}$ to remove the diameter dependence), where $\mathrm{m}=0.524$, which is the exponent of the power-law fit to our entire down-selected crater population including craters from Utopia and Isidis (Table 2). Plotted in Figure 10 are the CDFs of $d_{r} / D^{m}$ for the complex pitted-material craters $(D \geq 12 \mathrm{~km}, \mathrm{n}=56)$ residing in each of the two target types. The Kolmogorov-Smirnov (KS) statistic was computed for the comparison between the CDFs for craters in "strong" and "weak targets", finding a $p$-value of 0.26 , with deeper craters in the "weak" category $\left(d_{r} / D^{m}=0.345+/-0.025\right)$ when compared with the "strong" category $\left(d_{r} / D^{m}=0.335+/-0.023\right)$. This is contrary to the 
majority of previous results (Pike 1980a; Stewart and Valiant 2006; Boyce et al., 2006; Robbins and Hynek 2012b).

\section{[Figure 10]}

In the two-sample KS test, the null hypothesis is that both CDFs are sampled from the same distribution. A $p$-value of $\sim 26 \%$ suggests that the computed KS statistic, which is an estimate of the difference between two CDFs, is large enough to occur $26 \%$ of the time if the null hypothesis is true. This suggests there is a low probability that the two CDFs are drawn from different distributions (i.e., repeating the experiment, the difference between CDFs for strong and weak targets would occur $26 \%$ of the time if the two crater populations sample the same distribution). Using the more sensitive Anderson-Darling (AD) test, we find a slightly larger $p$-value of $\sim 27 \%$. If the "strong" category instead consists of units described as having lava plains and flows as well as volcaniclastics in Tanaka et al. (2014) (e.g., AHv, Amazonian volcanic [Av], Amazonian volcanic edifice [Ave], eHv, Hesperian volcanic edifice $[\mathrm{Hve}], 1 \mathrm{Av}, 1 \mathrm{Avf}$, late Hesperian volcanic $[\mathrm{H} \mathrm{Hv}]$, late Hesperian volcanic field [lHvf], late Noachian volcanic [ $1 \mathrm{Nv}]$, Noachian highland edifice [Nhe], Noachian volcanic edifice [Nve]), then the KS-test finds a $p$-value of $\sim 6.3 \%$ and the $\mathrm{AD} p$-value is $\sim 10 \%$, which are still too large to be considered significant. We note that if the previous geologic maps for Mars (Scott and Tanaka, 1986; Greeley and Guest, 1987) are used instead to categorize targets according to strength, we again find that neither test suggests a statistically significant difference in distributions of $d_{r} / D^{m}$. This is also the case when we instead identify "strong" terrains to be the high-strength units proposed by Bandfield et al. (2013). 
In conclusion, among the 56 pitted material complex craters of the refined sample population, and including the five complex craters from Utopia and Isidis, we do not find a statistically-significant tendency for deeper craters to form in stronger targets. On the contrary, we find that pitted material-bearing craters forming in weaker targets are slightly deeper, on average, but emphasize that this difference is not statistically significant based on the results of the KS and $\mathrm{AD}$ tests. Therefore, the variation in crater depth in our refined sample population (even when including Utopia and Isidis craters) cannot be explained by the effects of target properties alone. It is important to note, however, that this conclusion hinges on the assumption that lava plains are stronger and thereby mitigate gravitationallydriven collapse, and that these "stronger" target materials are sufficiently thick to influence this process for all craters classified into the "strong" target category. Recent numerical studies are now showing that some layered units, such as the layered volcanics observed in central uplifts and exposures in the walls of Valles Marineris (e.g., Caudill et al., 2012; Quantin et al., 2012) may be weaker than previously thought. In particular, layering may introduce preferential zones of weakness along bedding plains that leads to enhanced faulting and thereby enhanced gravitationally-driven collapse during crater modification (Pike, 1981; Hopkins et al., 2015).

Lastly, we note that the Robbins and Hynek (2013) deepest "southern hemisphere" relationship plots toward the bottom right of the graph in Figure 9. This may be largely a consequence of this particular sample population being derived specifically from the most heavily-cratered terrains on Mars, which is consistent with what is interpreted to be the weakest surfaces. A discontinuous mega-regolith would only be on the order of $\sim 1 \mathrm{~km}$ or so in thickness (McEwen et al., 2008). As such, this weak near-surface layer would 
preferentially affect craters at smaller diameters (c.f., relationships in Fig. 8a) causing a decrease in the coefficient and increase in the exponent.

4.2.4 Variations due to strength of gravity

Depth vs. diameter scaling relationships for well-preserved craters on other terrestrial bodies vary widely (Robbins et al. 2017). Studies of well-preserved lunar complex craters generally find a much smaller exponent than what is typical of martian values $(0.25 \leq m \leq 0.35)$ and a much larger coefficient $(0.8 \leq c \leq 1.6)$, indicating much deeper craters that deepen far more gradually with increasing diameter (e.g., Pike, 1981; Kalynn et al., 2013). This is as would be expected on a low-gravity body in which crater collapse is not as extensive. Using laser altimetry elevations measured from well-preserved complex craters on Mercury, Susorney et al. (2016) also found a larger coefficient and smaller exponent on this lower-gravity body: $c=1.02 \pm 0.10$ and $m=0.20 \pm 0.03$. We refer the reader to a recent comprehensive review of depth vs. diameter scaling relationships by Robbins et al. (2017) for more comparisons.

4.2.5 Summary of the sources of variation on reported complex crater depth vs. diameter scaling relationships

We summarize the sources of variation in depth vs. diameter scaling relationships by referring to the parameter space plot in Figure 9.

(1) The refinement steps for "problematic" craters generally lead to an overall reduction in depth, lowering the coefficient $c$ (a shift toward the bottom of Fig. 9). To the extent that craters are more heavily sampled at small diameters, this tends to increase the exponent $m$ (toward the right on Fig. 9). 
(2) Crater shallowing from infilling corresponds largely to a downward shift on Fig. 9 (smaller coefficient, constant exponent), consistent with previous studies (Boyce and Garbeil, 2007).

(3) Including more transitional craters, as well as small-diameter complex craters in highstrength targets, causes the coefficient to increase and exponent to decrease: a shift toward the upper left in Fig. 9.

(4) Lower surface gravity leads to deeper craters and a more gradual increase in depth with increasing diameter (a shift toward the upper left in Fig. 9; e.g., Robbins et al. (2017)).

(5) As mentioned earlier, it is worth remembering that use of coarser elevation models (e.g., MOLA MEGDR vs. PEDR), or failure to ensure that rim elevations are directly sampled by laser altimetry spots, would likely result in a shallowing of measured depths (a shift downward on Fig. 9; Robbins and Hynek, 2013).

Finally, we emphasize the importance of applying a preservation criterion that ensures the initial post-impact formation crater depth is measured, so that crater preservation state is held nearly as a constant over the entire diameter range. This is likely not the case for previous studies, which used other preservation criteria that do not include a means of verifying the presence of primary crater floor deposits. Because deeper, well-preserved craters tend to have smaller diameters, we can expect a systematic bias in studies that do not sufficiently control for preservation state. In particular, this leads to a scaling law with a higher coefficient and smaller exponent (a shift to the upper left in Fig. 9).

\section{Conclusions}

Craters containing pitted materials have provided new insights and constraints on a MOLA-based depth vs. diameter scaling relationship for "relatively unmodified" craters 
on Mars. Notably, pitted material-bearing craters are shown here to be among the deepest craters on Mars when compared to thousands of depth measurements for craters from previous studies. This lends further support to the hypothesis initially put forth by Tornabene et al. (2007; 2012), that these materials are the primary crater-fill deposits (e.g., a volatile-rich impact melt-bearing breccia deposit) (McEwen et al., 2007a; Tornabene et al., 2007, 2012; Boyce et al., 2012; Denevi et al., 2012; Mouginis-Mark and Boyce, 2012; Sizemore et al., 2017). We conclude that the upper surface of the pitted materials represents the upper surface of the primary crater-fill impactites, making these craters an ideal sample population from which to measure the rim-to-floor elevation difference that represents the initial post-formation crater depth.

The scaling relationships for maximum $\left(d_{r}\right)$ and average $\left(d_{a}\right)$ rim-to-floor depth vs. diameter derived from our database of craters with pitted materials are shown to be broadly consistent with most previous estimates (to within two standard errors of our fit parameter values), but also exhibit some notable differences that cannot be accounted for by differences in methods alone. We have used these relationships as a "baseline" for comparison to other reported relationships, to understand the sources of variation on the power-law fit parameters as well as the variation in crater depth across the reported diameter range $(\sim 12-100 \mathrm{~km})$. These include the combined influences of all the following: (1) discarding "problematic" craters and refining measurements to avoid anomalous topographic features that otherwise skew or distort depth estimates; (2) including craters that are partially infilled; (3) target strength variations; (4) using elevation data products that insufficiently resolve craters; (5) variations in surface gravity; and (6) diameter- 
dependent preservation sampling bias in samples of the "freshest craters" and "deepest craters".

Because we have worked with a sample population for which preservation state is nearly uniform, the cause of the variation in depth for any given diameter is likely related either to (a) an inherent property of crater formation that generates the pitted materials, or (b) intrinsic variation in the impact parameters, such as impact angle or velocity, or (c) a target strength property that is not readily recognized from orbital datasets alone (e.g., preferential subsurface zones of weakness). We note that this study cannot account for any additional influences on the initial post-impact formation crater depth that may be a consequence of whether the impact produced pitted vs. non-pitted and lunar-like impactite deposits (e.g., Pangboche Crater: a well-preserved crater with non-pitted and lunar-like crater-fill deposits; see Mouginis-Mark, 2015; Tornabene et al., 2012). However, nonpitted and lunar-like melt deposits are considerably rarer based on a survey by Tornabene et al. (2012) (approximately < 5\%); as such, we consider the complex crater scaling relationship derived from pitted material-bearing craters in this study to be highly representative of the global population of relatively unmodified craters. Therefore, these relationships may be applied to regional and global studies where this specific morphometric relationship may be of great use (e.g., gauging the type and extent of crater degradation, and for constraining numerical models focused on crater formation and landscape evolution).

\section{Acknowledgements}

This work was supported by NSERC DG and Canadian Space Agency CO-I grants. We would also like to thank the following groups or people: Ms. Deanne Daigle for her kind assistance with some discussion and application of some of the statistical methods related 
to this paper; and Dr. Joshua Bandfield for providing a shape layer that includes regions interpreted to be high-strength based on thermophysical properties reported in Bandfield et al. (2013). Last, but not least, we thank Dr. Nadine Barlow and Dr. Peter MouginisMark for their insightful and constructive reviews of this paper leading to publication in this journal. 
Table 1. Comparisons of this study and other MOLA-based depth vs. diameter scaling relationships for the "deepest" complex craters

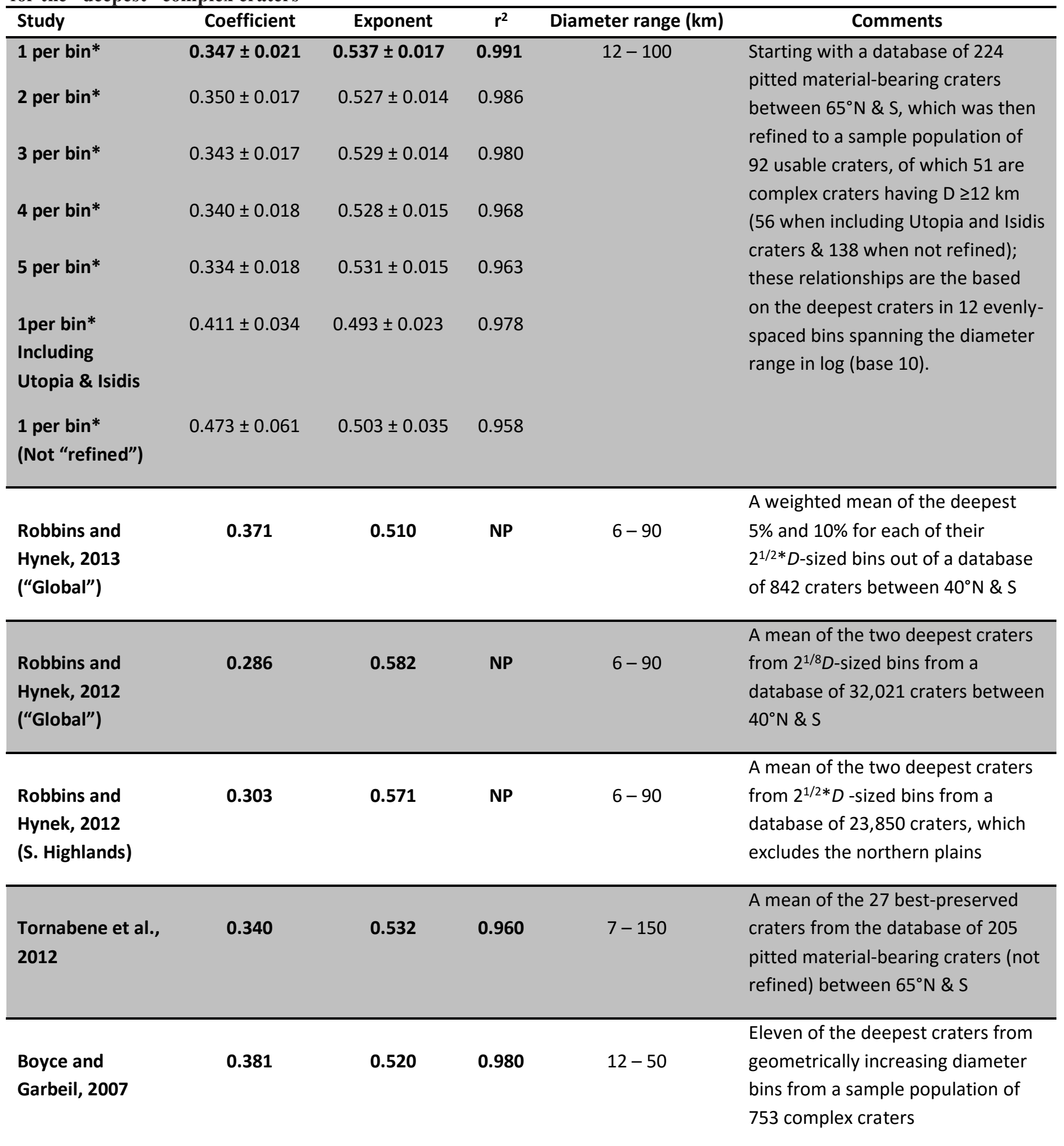

\footnotetext{
* - A maximum \# per bin as some bins may not possess the \# of craters indicated based on availability within that bin. NP - Not Provided.
} 
Table 2. Comparisons of this study and other MOLA-based depth vs. diameter scaling relationships for the Mean ("freshest craters") complex craters

\begin{tabular}{|c|c|c|c|c|c|}
\hline Study & Coefficient & Exponent & $r^{2}$ & Diameter range $(\mathrm{km})$ & Comments \\
\hline ("Refined") & $0.323 \pm 0.017$ & $0.538 \pm 0.016$ & 0.960 & $12-100$ & $\begin{array}{l}\text { Starting with a database of } 224 \\
\text { pitted material-bearing craters }\end{array}$ \\
\hline $\begin{array}{l}\text { Robbins and } \\
\text { Hynek, } 2012 \\
\text { ("Global") }\end{array}$ & 0.250 & 0.527 & NP & $6-90$ & $\begin{array}{l}\text { Power-law-fit to all Robbins and } \\
\text { Hynek (2012a) Class } 3 \text { and } 4 \\
\text { craters from their database of } 976 \\
\text { of the } 32,021 \text { measurable complex } \\
\text { craters between } 40^{\circ} \mathrm{N} \& \mathrm{~S}\end{array}$ \\
\hline $\begin{array}{l}\text { Whitehead et al., } \\
2010\end{array}$ & 0.250 & 0.530 & 0.530 & $7.6-234$ & $\begin{array}{l}\text { Mean of } 367 \text { "fresh craters" based } \\
\text { on an inspection } 1336 \text { craters from } \\
\text { the Barlow (2000) database. }\end{array}$ \\
\hline $\begin{array}{l}\text { Boyce and } \\
\text { Garbeil, } 2007\end{array}$ & 0.315 & 0.520 & 0.820 & $12-50$ & $\begin{array}{l}\text { Power-law-fit to the } 5 \text { deepest } \\
\text { craters per each } D \text { bin from their } \\
\text { database of } 753 \text { complex craters }\end{array}$ \\
\hline $\begin{array}{l}\text { Stewart and } \\
\text { Valiant, } 2006 \\
\text { (Lunae) }\end{array}$ & 0.266 & 0.570 & NP & $7-50$ & $\begin{array}{l}\text { See Stewart and Valiant, } 2006 \\
\text { (Lunae) }\end{array}$ \\
\hline $\begin{array}{l}\text { Stewart and } \\
\text { Valiant, } 2006 \\
\text { (Solis) }\end{array}$ & 0.302 & 0.520 & NP & $7-50$ & $\begin{array}{l}\text { See Stewart and Valiant, } 2006 \\
\text { (Solis) }\end{array}$ \\
\hline
\end{tabular}




\begin{tabular}{|c|c|c|c|c|c|}
\hline $\begin{array}{l}\text { Garvin et al., } \\
2003\end{array}$ & 0.360 & 0.490 & NP & $7-100$ & $\begin{array}{l}\text { Mean of the top } 25 \% \text { deepest } \\
\text { craters from a sample population of } \\
\sim 6000 \text { craters }\end{array}$ \\
\hline
\end{tabular}

NP - Not Provided. 


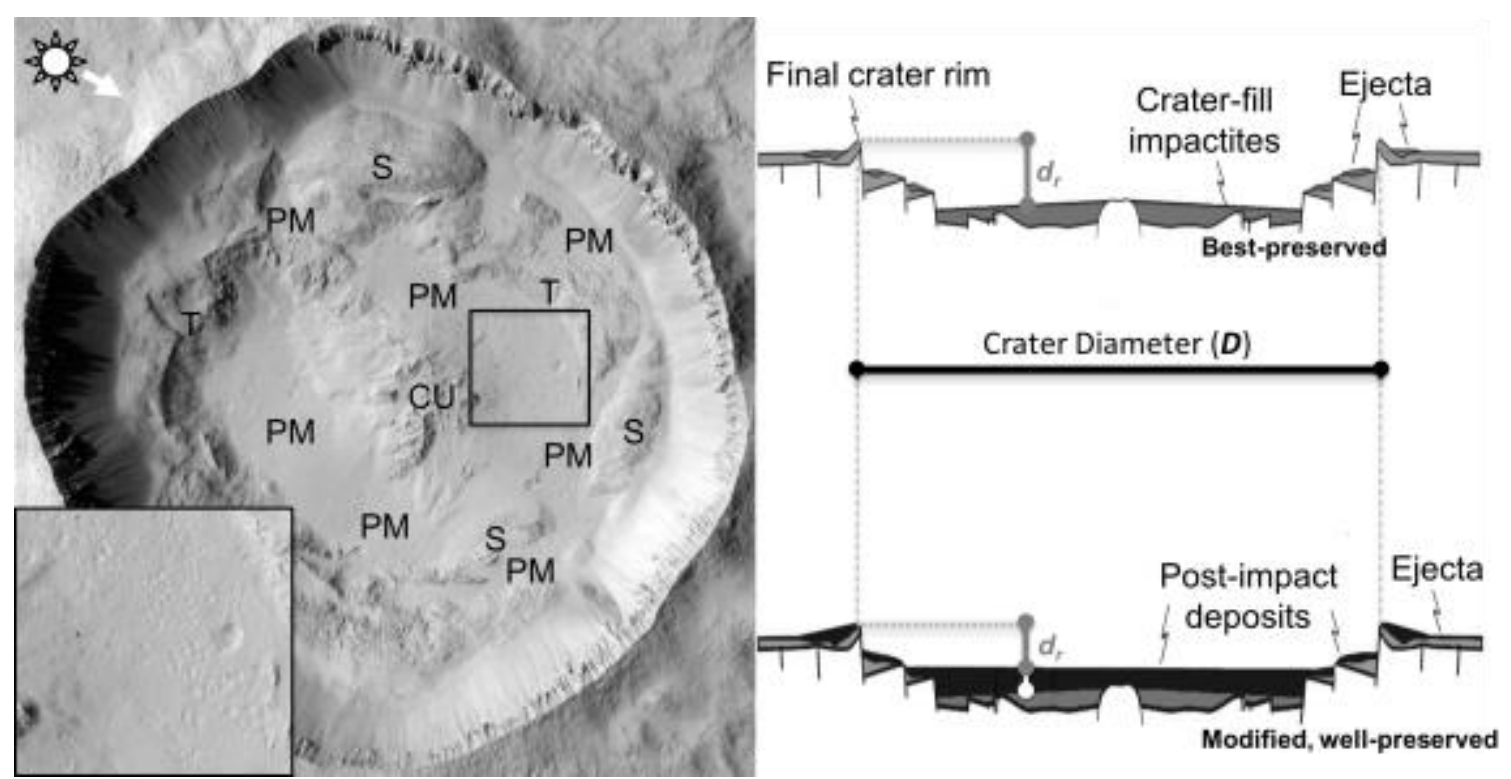

Figure 1. Example of pitted materials from Zunil Crater $(\mathrm{D}=10.2 \mathrm{~km})$ (left) and cross-sections of complex craters illustrating the difference between the maximum rim-to-floor depth $\left(d_{r}\right)$ of unfilled (above right) and partially-infilled craters (below right). Zunil is one of the best-preserved craters for its size-class on Mars and is a type example for the crater-related pitted materials (magnified inset on lower left) $(\mathrm{PM}=$ pitted materials; $\mathrm{S}=$ slump; $\mathrm{T}=$ terrace; $\mathrm{CU}=$ central uplift). The top-right cross-section shows a nearly "pristine" crater with minor amounts of modification from erosion or deposition, but still preserves recognizable features consistent with their primary crater-fill deposits (i.e., impactites). Such craters should exhibit the least-modified, and among the very deepest, post-formation crater depths. The quantity $d_{r}$ is defined as the difference in elevation between the maximum crater rim elevation and the lowest elevation on the crater floor (grey); the lower-right cross-section indicates a smaller rim-to-floor depth due to, in this example, shallowing from the deposition of airfall-style post-impact deposits (black), which have completely obscured the primary deposits (grey). Image credits: NASA/JPL-CALTECH/MSSS and crosssection modified after Osinski et al. (2005). 


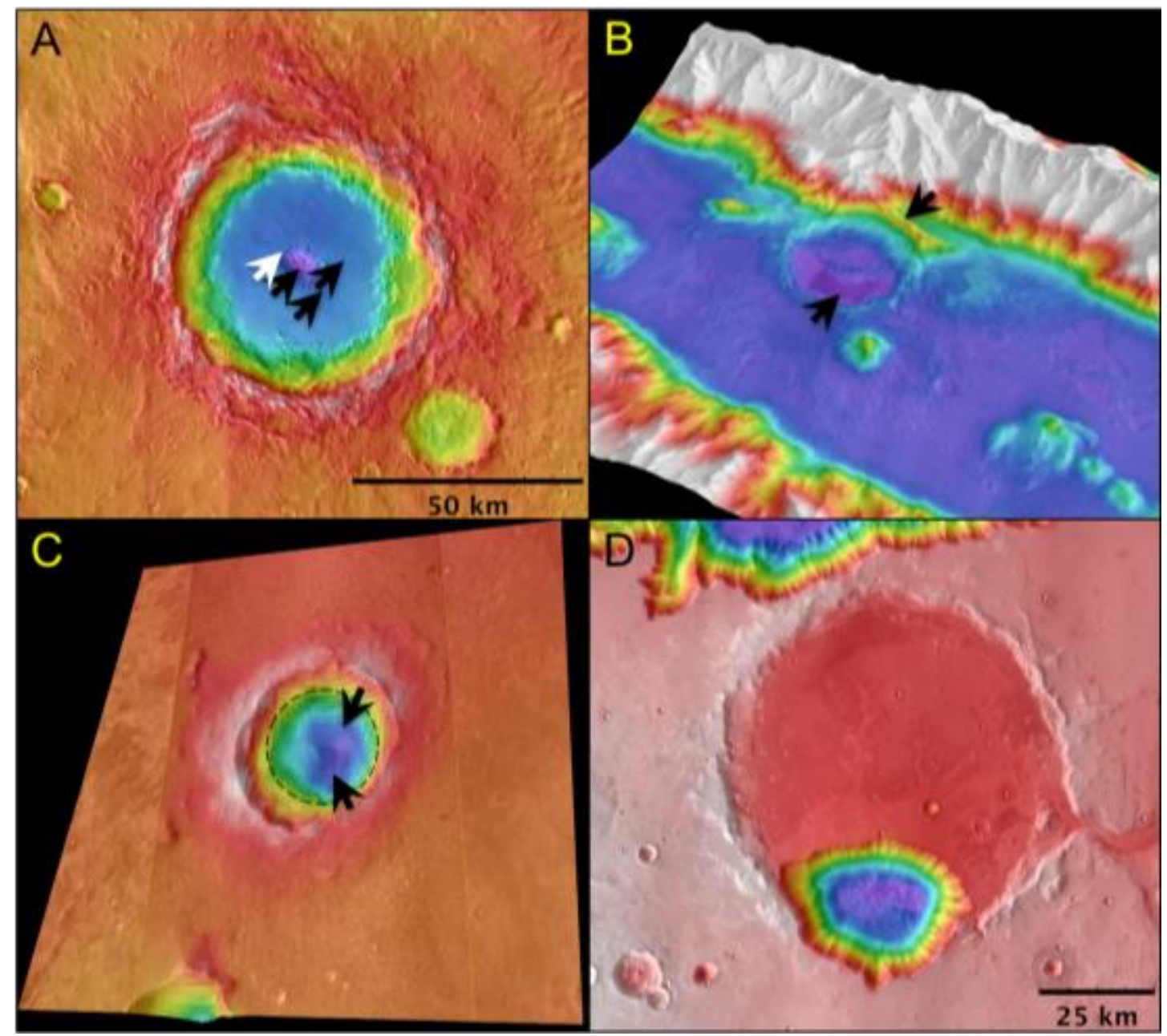

Figure 2. Craters with a "problematic" $d_{r}$ and $D$ measurement selected from Tornabene et al. (2012), Boyce et al. (2005), and Robbins and Hynek (2012b) databases observed with the MOLA MEGDR colorized DTM overlain on the THEMIS daytime IR global mosaic. These examples include one crater in which crater depth measurement can be refined by avoiding anomalous features (A) and 2 craters that were excluded owing to unusual features and conditions (B-C). A) A $~ 60-\mathrm{km}$ diameter crater located at $113.47^{\circ} \mathrm{E}, 13.67^{\circ} \mathrm{S}$. Black arrows point to elevation lows in the central pit and overprinting impact craters on the floor. An elevation outside of these features was selected to better represent the maximum rim-tofloor depth. For this particular example, an elevation was selected that specifically falls on the crater-fill deposits and off the depression of the central pit (i.e., an elevation of -297.74 meters; white arrow). There are 122 MOLA PEDR shots that lie in the central pit with a maximum depth recorded at -968.4 meters; using elevations in the central pit would therefore indicate a depth that is $\sim 670$ meters too deep. B) A 3D perspective of a remarkably well-preserved, unnamed, $\sim 22-\mathrm{km}$ pitted material bearing crater in Valles Marineris $\left(302.77^{\circ} \mathrm{E} 16.00^{\circ} \mathrm{S}\right)$ that has been severely over-steepened due to the pre-existing slope and topography in this region. C) A $\sim 15-\mathrm{km}$ crater from the Boyce et al. (2005) database located at $285.50^{\circ} \mathrm{E}$, $17.42^{\circ} \mathrm{N}$ that exhibits a highly non-uniform floor elevation possibly due to pre-impact target control (e.g., possibly a pre-existing impact crater [dashed-line] $\sim 9 \mathrm{~km}$ in diameter), and D) Robbins and Hynek (2012b) crater database entry $18-000066$ located at $308.53^{\circ} \mathrm{E}, 10.08^{\circ} \mathrm{S}$. Inspection of this extremely deep $\sim 35-\mathrm{km}$ wide feature reveals that it is most likely tectonic and not an impact structure. The feature is non-circular, lacks a raised topographic rim, ejecta blanket, and any features normally associated with a complex crater. Given the feature also occurs in the vicinity of Valles Marineris (to the North), it likely represents a tectonic collapse structure. Image credits: NASA/JPL-CALTECH/GSFC/ASU. 


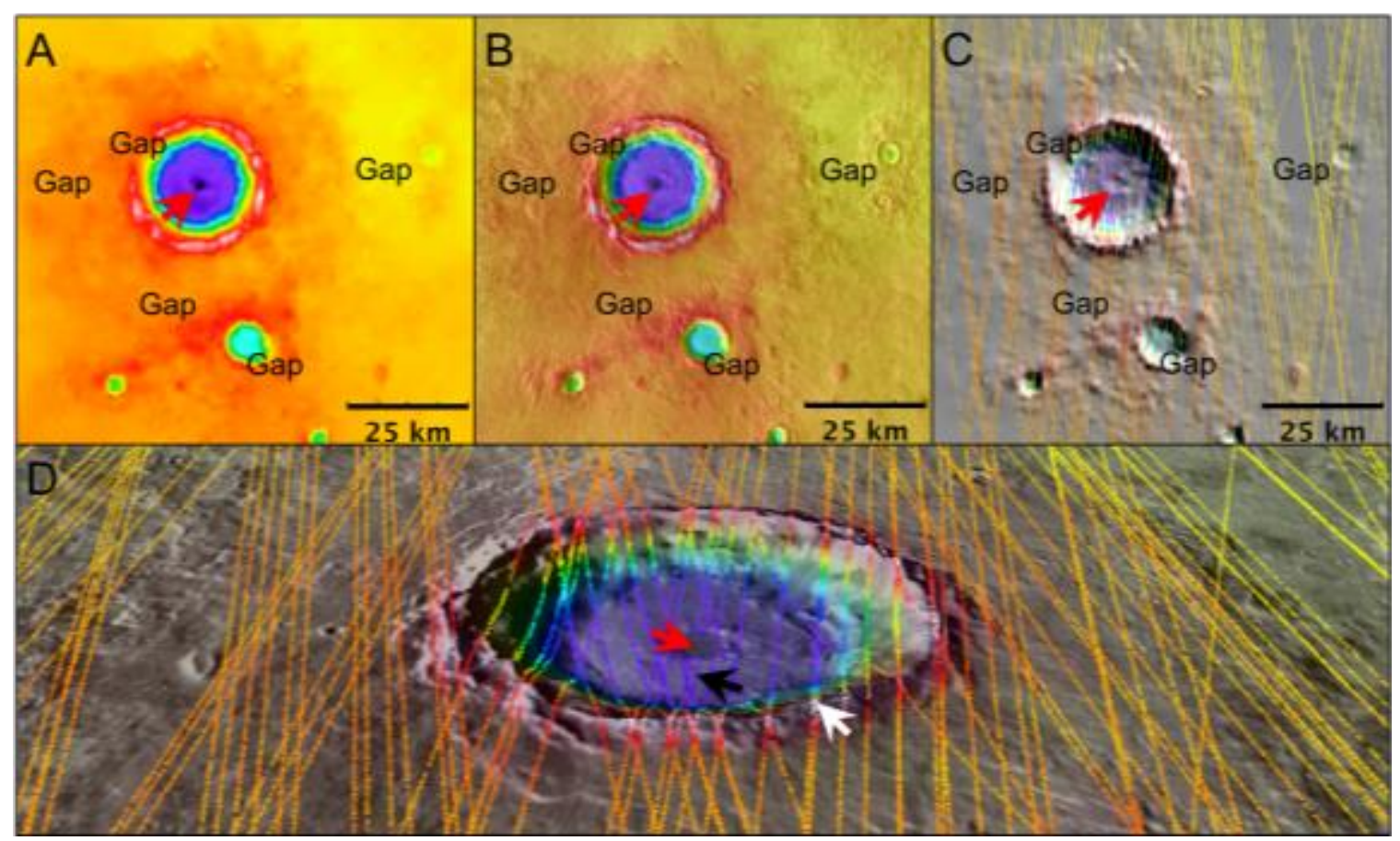

Figure 3. An unnamed $\sim 26-\mathrm{km}$ diameter pitted material-bearing crater located in Acidalia Planitia $\left(329.58^{\circ} \mathrm{E}\right.$, $36.58^{\circ} \mathrm{N}$ ) for which $d_{r}$ was measured by avoiding a central pit. Different combinations of datasets are shown here to illustrate challenges in regard to the assessment of coverage (e.g., gaps) and effects that artificially distort depth (see text for more details). A) MOLA MEGDR colorized DTM. B) previous image superimposed on THEMIS daytime TIR. C) Colorized MOLA PEDR tracks superimposed on a MOLA MEGDR shaded relief map. D) A 3D perspective of the crater based on MOLA PEDR tracks on the THEMIS daytime TIR mosaic draped over the MOLA MEGDR dataset (SW view with a V.E. of $\sim 7 x$ ). The white arrow indicates the location of the maximum rim elevation, while the black arrow indicates where the floor elevation was measured instead (elev: -5482.65 meters) avoiding the central pit feature (red arrow, $41 \mathrm{~m}$ lower) Note that data gaps in MOLA coverage are difficult to recognize in both panels A and $\mathrm{B}$, but are readily identified in $\mathrm{C}$ and D. Image credits: NASA/JPL-CALTECH/GSFC/ASU. 
A

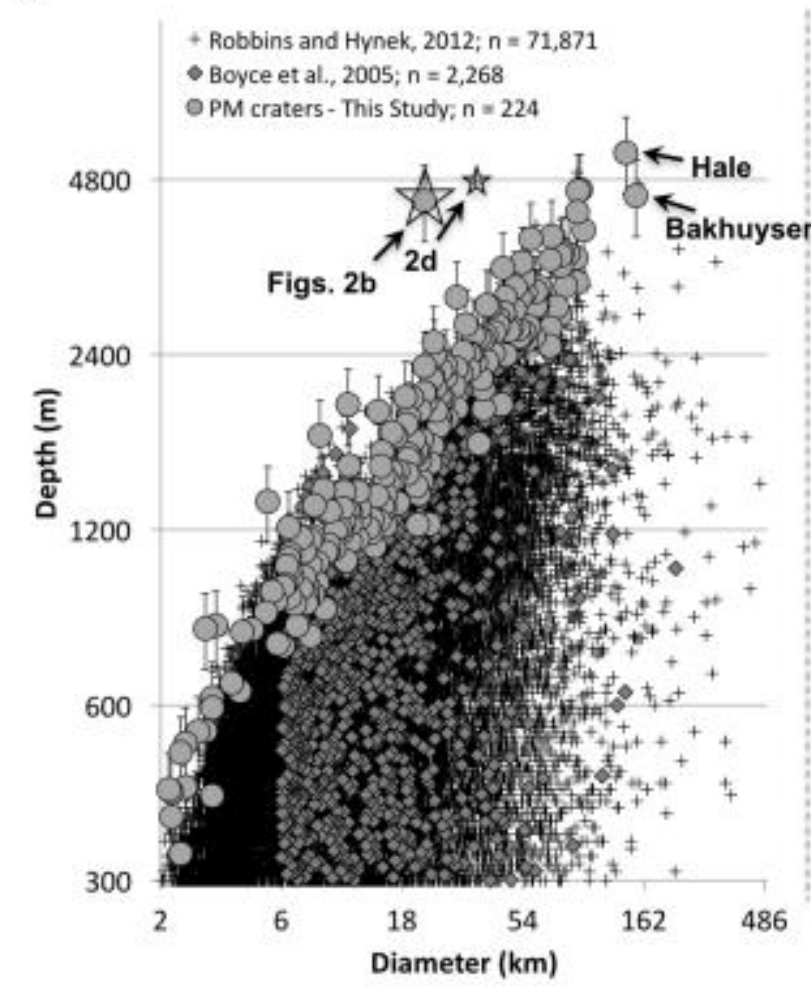

B

+ Robbins and Hynek, 2012; $n=71,871$

- Boyce et al., 2005; $n=2,268$

" Robbins and Hynek, 2012 - PM crater

PM craters - This Study; $n=92$

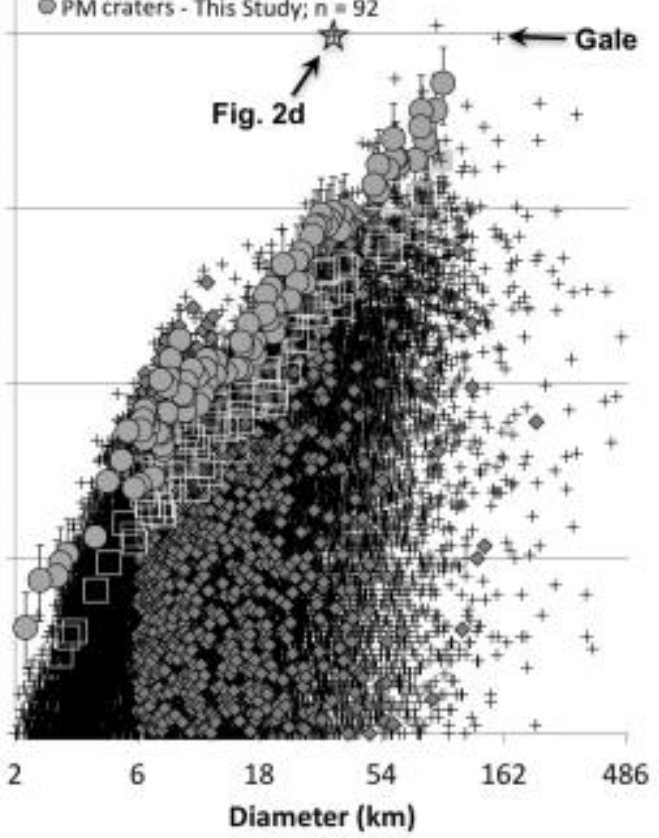

Figure 4. $\log$-Log (base 2) scatter plots of depth vs. diameter for pitted material-bearing craters $>2 \mathrm{~km}$ in diameter (grey circles, this study), and 2,268 craters from Boyce et al., (2005) (dark grey diamonds) and 71,871 of 75,472 measurements from Robbins and Hynek (2012a; 2012b) (crosses and white squares). A) Plot comparing the depths and diameters of all 224 pitted material-bearing craters using a simple maximum rim-to-floor depth, and B) plot of the depths vs. diameters of the 92 pitted material-bearing craters after refining measurements to avoid depth-enhancing features and omitting "problematic" craters. This plot includes Robbins and Hynek (2012a; 2012b) MOLA-based measurements for pitted material craters in this study (white squares) using an average (as opposed to maximum) rim-to-floor depth. The largest and deepest crater from the Robbins and Hynek (2012b) crater database is Gale Crater. At first, Gale appears to exhibit an initial post-impact formation crater depth. Upon careful inspection, it is another clear example of a modified, but well-preserved crater whose depth is not characteristic of its diameter, because: 1) clear examples of its primary crater-fill impactites are not preserved, 2) it is shown to have significant post-impact deposits that may be lacustrine in origin (e.g., Grotzinger et al. (2014)), and 3) it straddles a significant regional slope along the Mars global dichotomy boundary between the Southern Highlands and the Northern Lowlands, resulting in a north-south asymmetry in the morphometry of the crater. 

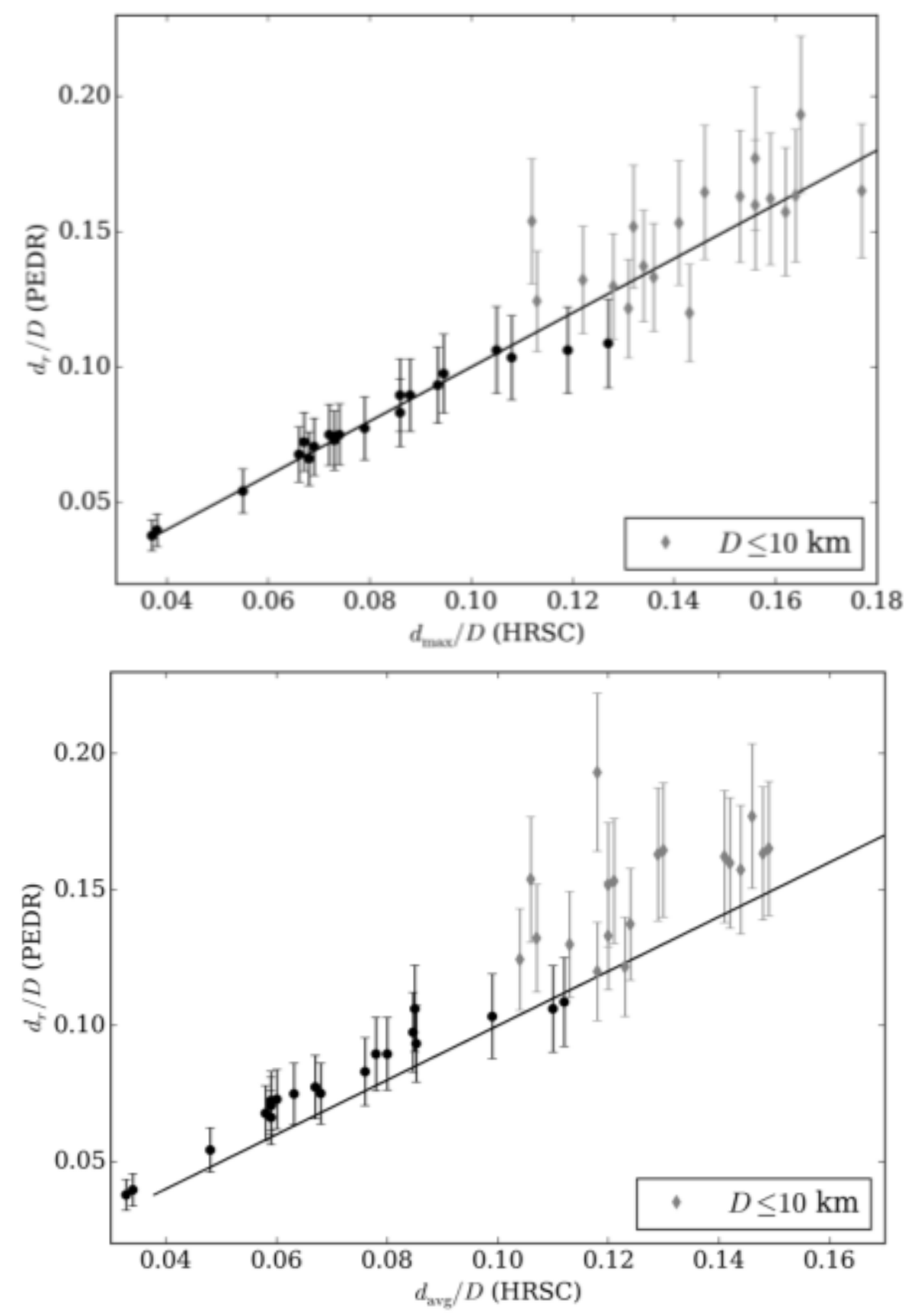

Figure 5. A) The maximum rim-to-floor depth/diameter $\left(d_{r} / D\right)$ measured using MOLA PEDR profiles, plotted against maximum rim-to-floor depth/diameter $\left(d_{\max } / D\right)$ measured from HRSC stereo-derived DTMs. B) Maximum rim-to-floor depth/diameter $\left(d_{r} / D\right)$ measured using PEDR profiles, plotted against average rimto-floor depth/diameter $\left(d_{\text {avg }} / D\right)$ measured from HRSC stereo-derived DTMs (see text). For $D>10 \mathrm{~km}$, we find that the PEDR and HRSC results agree to within $4.2 \%$ on average. Also for $D \leq 10 \mathrm{~km}$ (grey diamonds), we find that $d_{r} / D$ overestimates $d_{\text {avg }} / D$ by $\sim 13 \%$, on average. This is useful for comparing our results with previous estimates that may have used an average rim height instead of a maximum to measure rim-to-floor depth. The error bars are $\sim 15 \%$ of $d_{r}$, which is twice the average standard deviation of rim elevations (see text) and is also used in Figures 4, 6 and 8. 


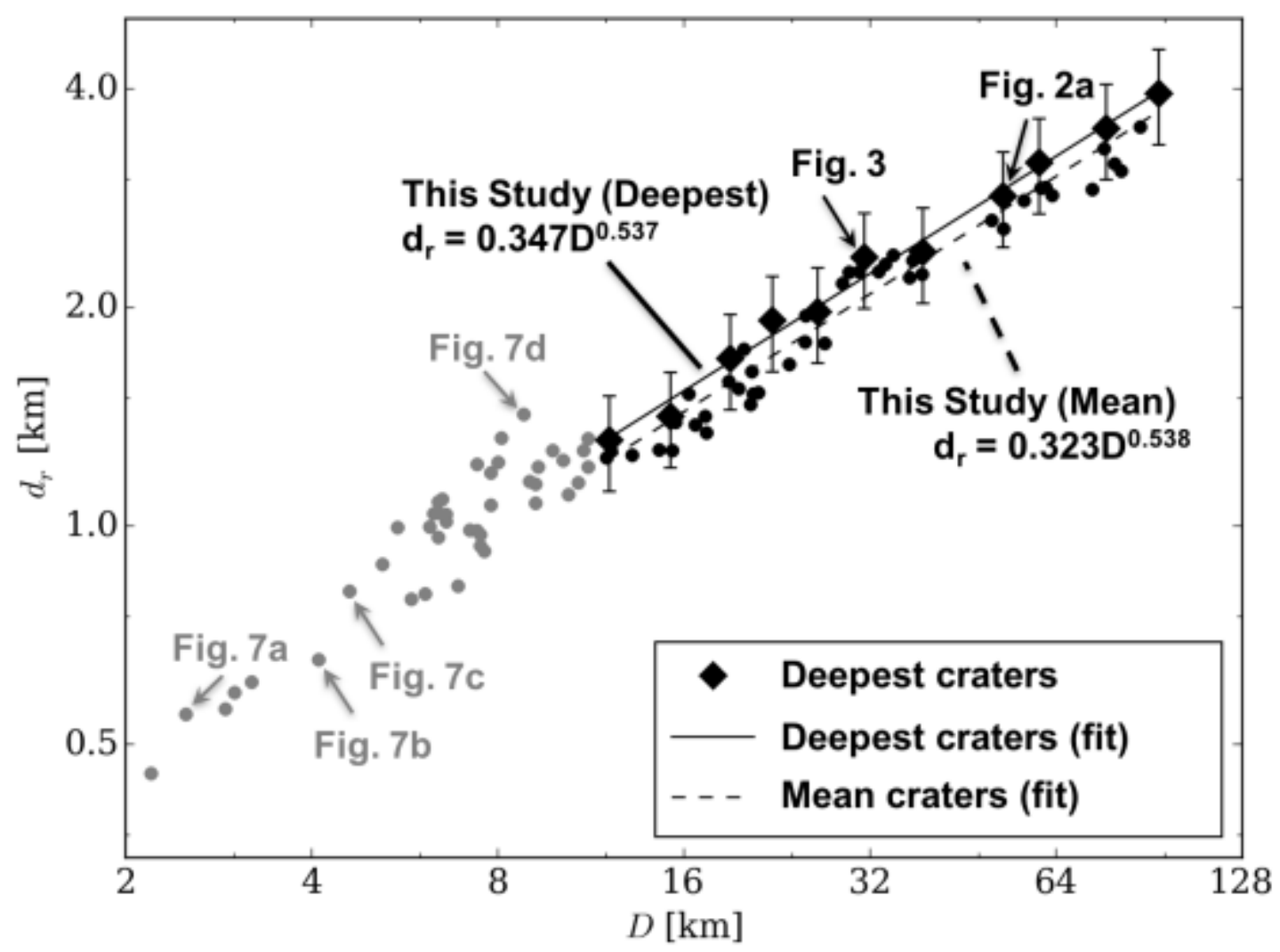

Figure 6. Log-log (base 2) MOLA PEDR-derived $d_{\mathrm{r}}$ vs. $D$ scatter plot based on the maximum rim-to-floor elevation. Included here are the power law fits for complex craters with $D \geq 12 \mathrm{~km}$ (black symbols). This includes the deepest craters (black diamonds), and a best-fit power law to the deepest craters (solid black diamonds and solid-line) and a mean $(n=51$; based on the refined sample population that excludes five complex craters from Utopia and Isidis - see text). Grey text and symbols are associated with pitted material-bearing craters $D<12 \mathrm{~km}$, most of which have morphologies that are transitional between simple and complex craters (see Fig. 7). Points with annotations refer to figures showing visible images of the indicated crater. 


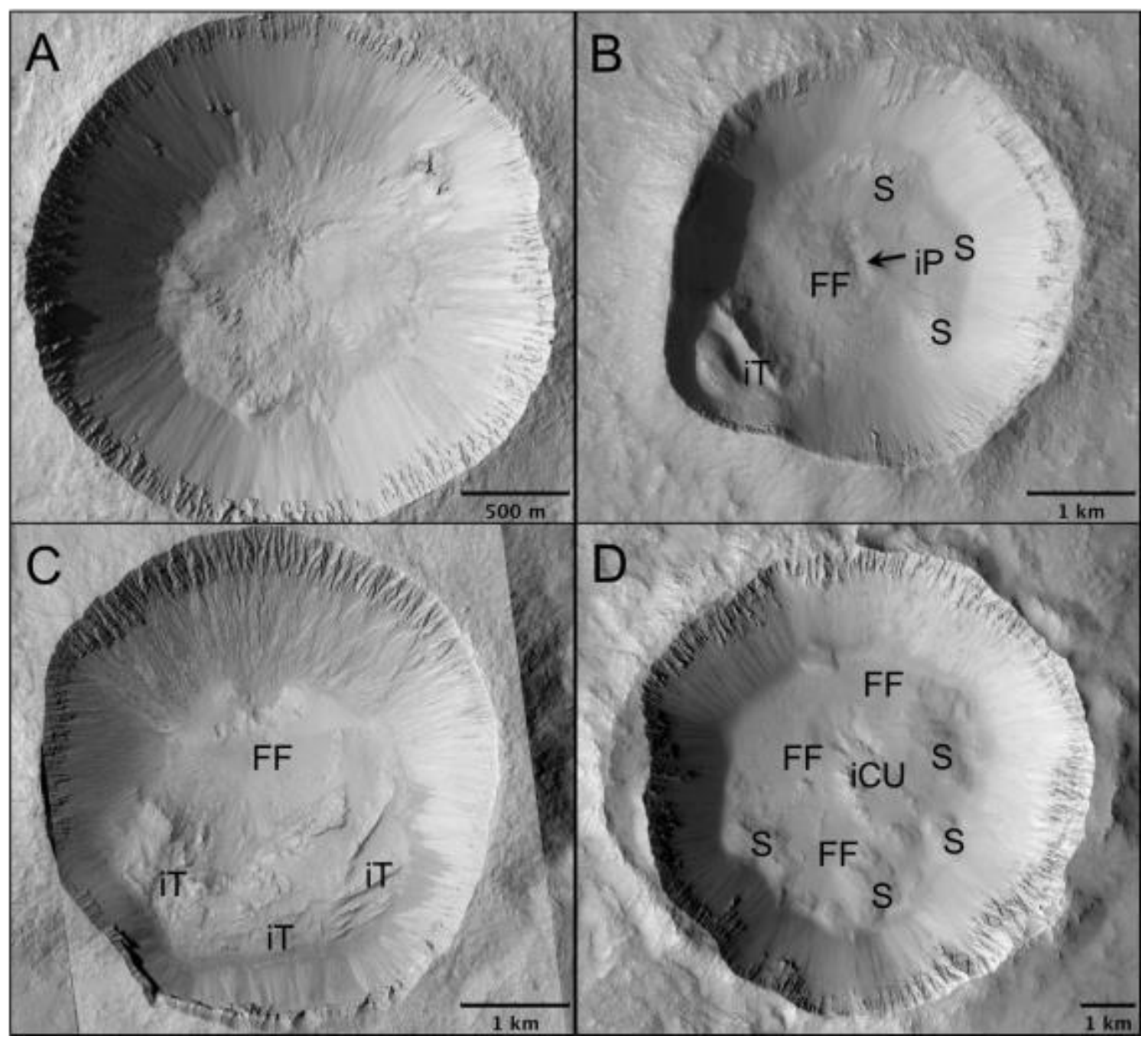

Figure 7. Examples of well-preserved pitted material-bearing simple and simple-to-complex transitional craters. A) Unnamed $2.5 \mathrm{~km}$ simple crater in Elysium Planitia (HiRISE image: PSP_009333_2025). This crater is most consistent with a simple crater morphology as it exhibits minimal slumping and a sloped floor and. B) Nayrn Crater ( $\mathrm{D}=\sim 4.1 \mathrm{~km} ; 123.3^{\circ} \mathrm{E}, 14.9^{\circ} \mathrm{N}$ ) in Elysium Planitia (HiRISE image: PSP_001660_1950). C) Istok Crater ( $\left.\mathrm{D}=\sim 4.6 \mathrm{~km} ; 274.2^{\circ} \mathrm{E}, 45.1^{\circ} \mathrm{S}\right)$ in Aonia Planum (HiRISE image: ESP_040251_1345). D) Unnamed 8.8-km crater in Terra Sabaea (CTX image: B08_012871_1566). Visible slumping (S), incipient terracing (iT), and flattening of the crater floor deposits (FF) are the morphologic hallmarks of a more complex crater morphology, including what appears to be an "incipient" central uplifts (iCU) and pits (iP). Image credits: NASA/JPL-CALTECH/University of Arizona and NASA/JPLCALTECH/MSSS. 


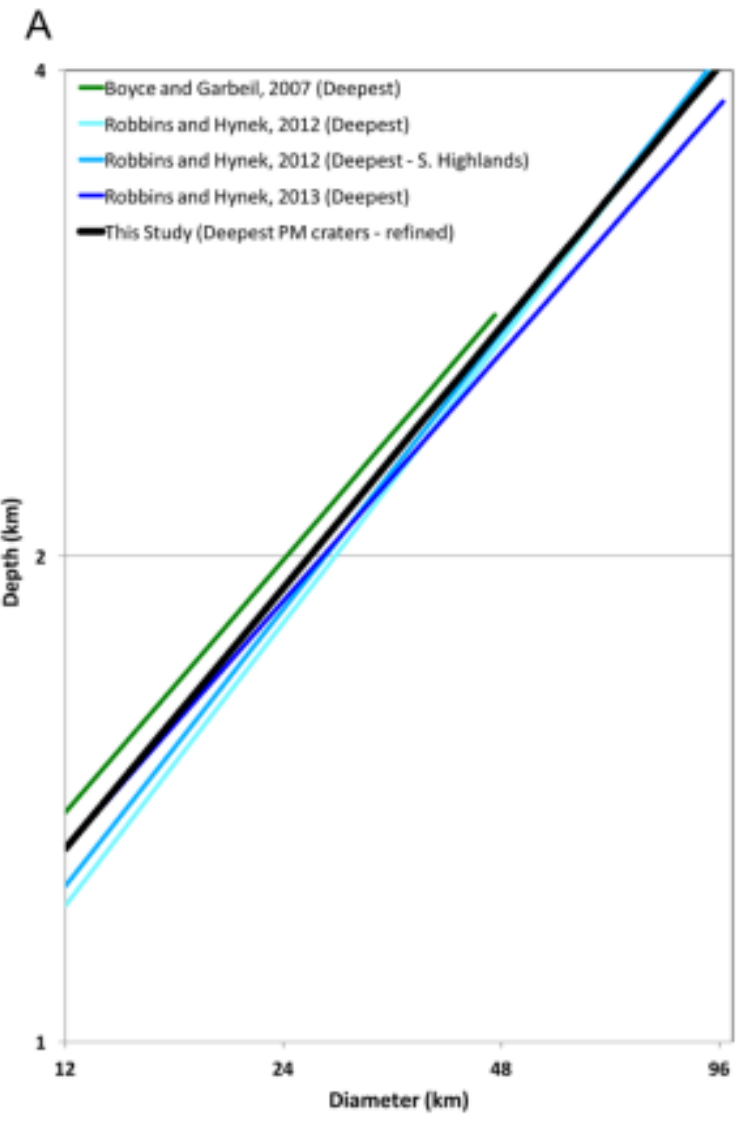

B

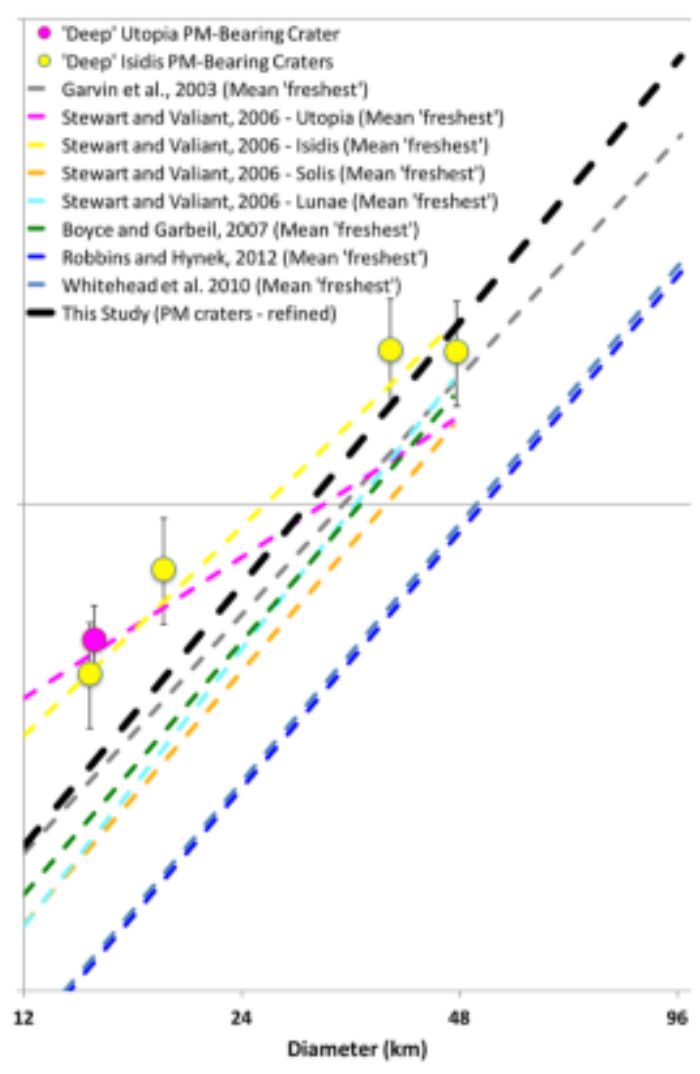

Figure 8. Complex crater depth vs. diameter scaling relationships for Mars $(D \geq 12 \mathrm{~km})$ based on MOLA PEDR and MEGDR measurements spanning 2003 to present (2017) and pitted material-bearing craters from the Utopia and Isidis regions. For the diameter range for each study, refer to Tables 1 and 2. A) "Deepest craters" relationships from Garvin et al. (2003), Boyce et al. (2007), Robbins and Hynek (2012a; 2013), and from this study. B) Global and regional averaged "freshest craters" relationships from Garvin et al. (2003), Boyce and Garbeil (2007), Whitehead et al., 2010, Robbins and Hynek (2012a), and including the region-specific relationships from Stewart and Valiant (2006). The reported complex crater scaling relationship from Stepinski et al. (2009) $(c=0.220, m=0.470)$ is not plotted here, but is plotted in Figure 9. 


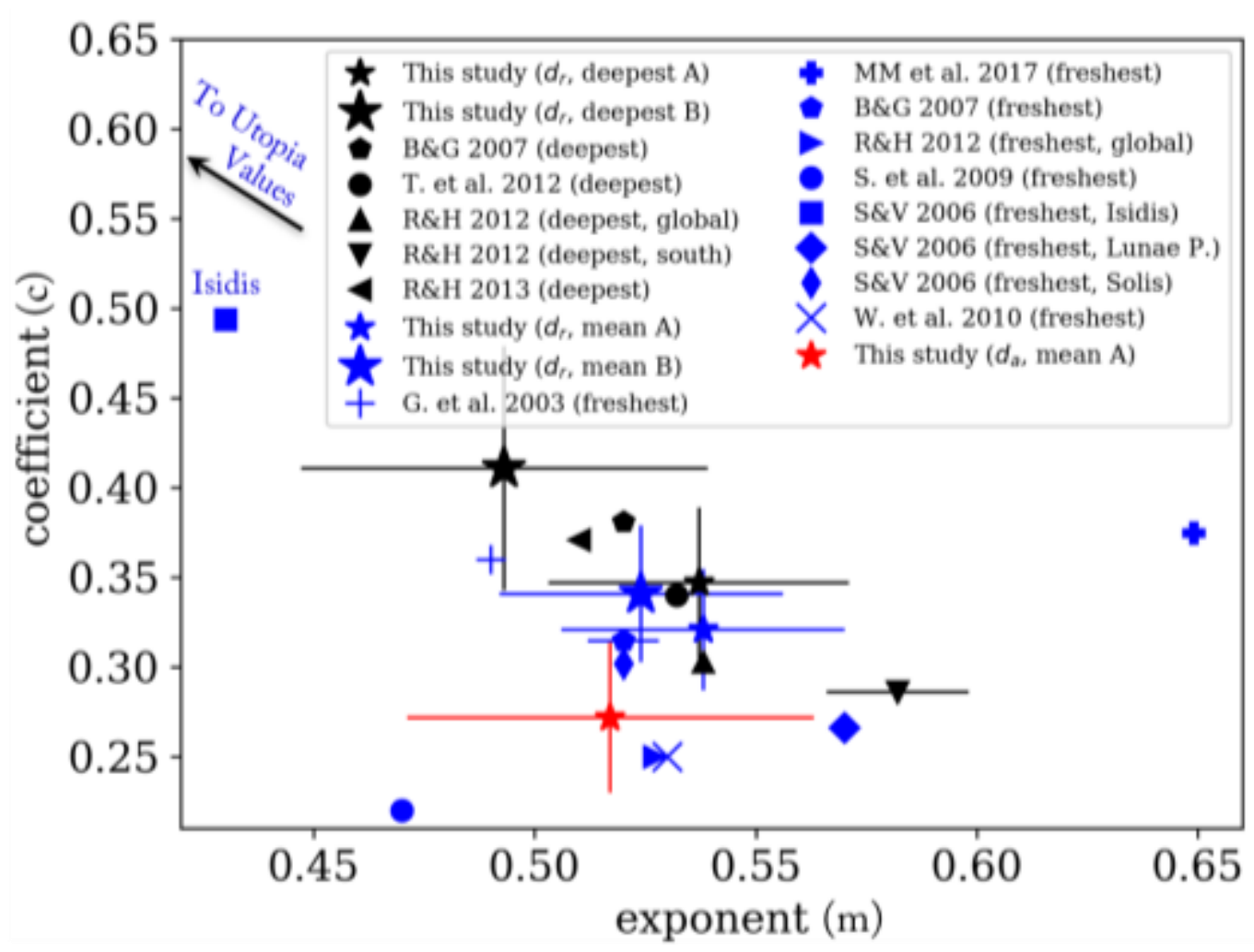

Figure 9. Power-law fit coefficient $(c)$ vs. exponent $(m)$ of complex crater depth vs. diameter scaling relationships based on MOLA (MEGDR and PEDR), CTX, and/or HRSC-derived DTMs spanning 2003 to present (2017): Boyce and Garbeil (B\&G), Tornabene et al. (T et al.), Robbins and Hynek (R\&H), Garvin et al. (G. et al.), Mouginis-Mark (MM et al.), Stepinski (S et al.), Stewart and Valiant (S\&V) and Whitehead et al. (W et al.). The relationship for craters in Utopia Planitia $(c=0.738, m=0.29)$ from Stewart and Valiant (2006) plots far to the upper left, and was omitted to avoid rescaling axes in a way that would not permit points in the main cluster to be distinguished (see Tables 1 and 2 for additional values for $c$ and $m$ ). Results from our study are represented using stars and error bars represent the formal standard error of our fit parameters multiplied by two. Error bars from previous studies are shown only if they were clearly explained; these do not necessarily represent the formal errors of fit parameters. Small stars represent the "set A" scaling laws that result when excluding craters in Utopia and Isidis (strong targets), while the larger stars represent the "set B" relationships that result when including these craters. Black points represent relationships based on the deepest craters per diameter bins. Blue points represent relationships measured from the $\mathrm{x} \%$ deepest craters in diameter bins or $\mathrm{x} \%$ deepest in a sample population as a whole (except in our study, in which craters were selected because they exhibit pitted materials and not because they are deepest). The blue and black stars represent results for maximum rim-to-floor depth $\left(d_{r}\right)$ based on MOLA PEDR data, whereas the red star represents the result for average rim-to-floor depth as measured in Robbins and Hynek (2012a) using the MOLA MEGDR DTM. 


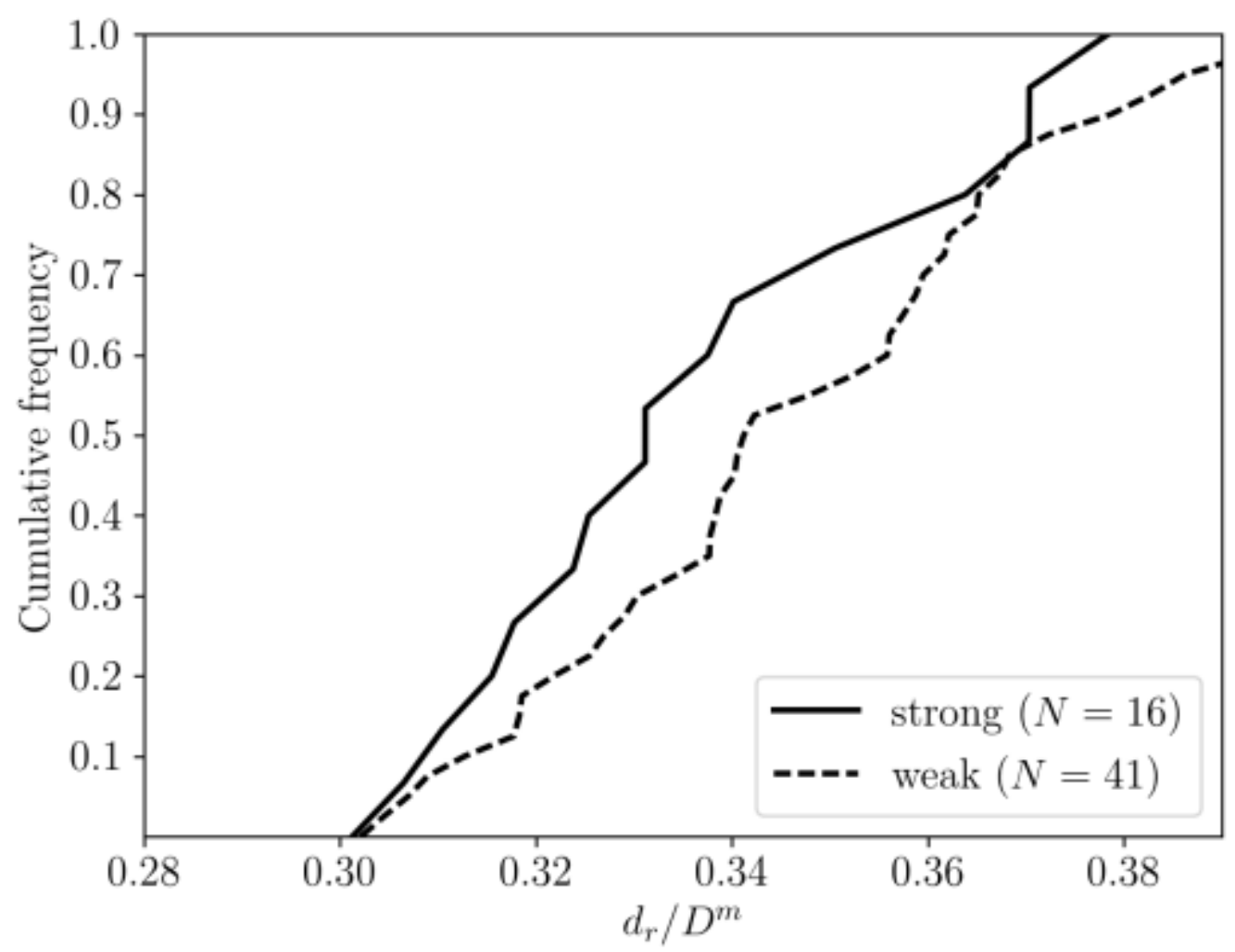

Figure 10. Cumulative frequency distribution plot for $d_{r} / D^{m}$ where $\mathrm{m}=0.524$, computed for all 56 complex craters remaining after the down-selection/refinement $(D \geq 12 \mathrm{~km})$ that formed in mapped units from Tanaka et al. (2014) interpreted to be "strong" materials (solid line) and craters that formed in the complement of this subset, interpreted as "weak" materials (dashed line). Plotted on the vertical axis is the fraction of all craters exceeding the values of $d_{r} / D^{m}$ on the horizontal axis. For example, two-thirds of craters that formed in the strong terrains have $d_{r} / D^{m} \geq 0.34$; this is true of only about $52 \%$ of craters that formed in weak terrains. Although this plot appears to suggest that craters forming in weaker targets are relatively deep (on average), neither of two statistical tests (i.e., Kolmogorov-Smirnov and AndersonDarling), indicates a statistically meaningful difference between these distributions. 


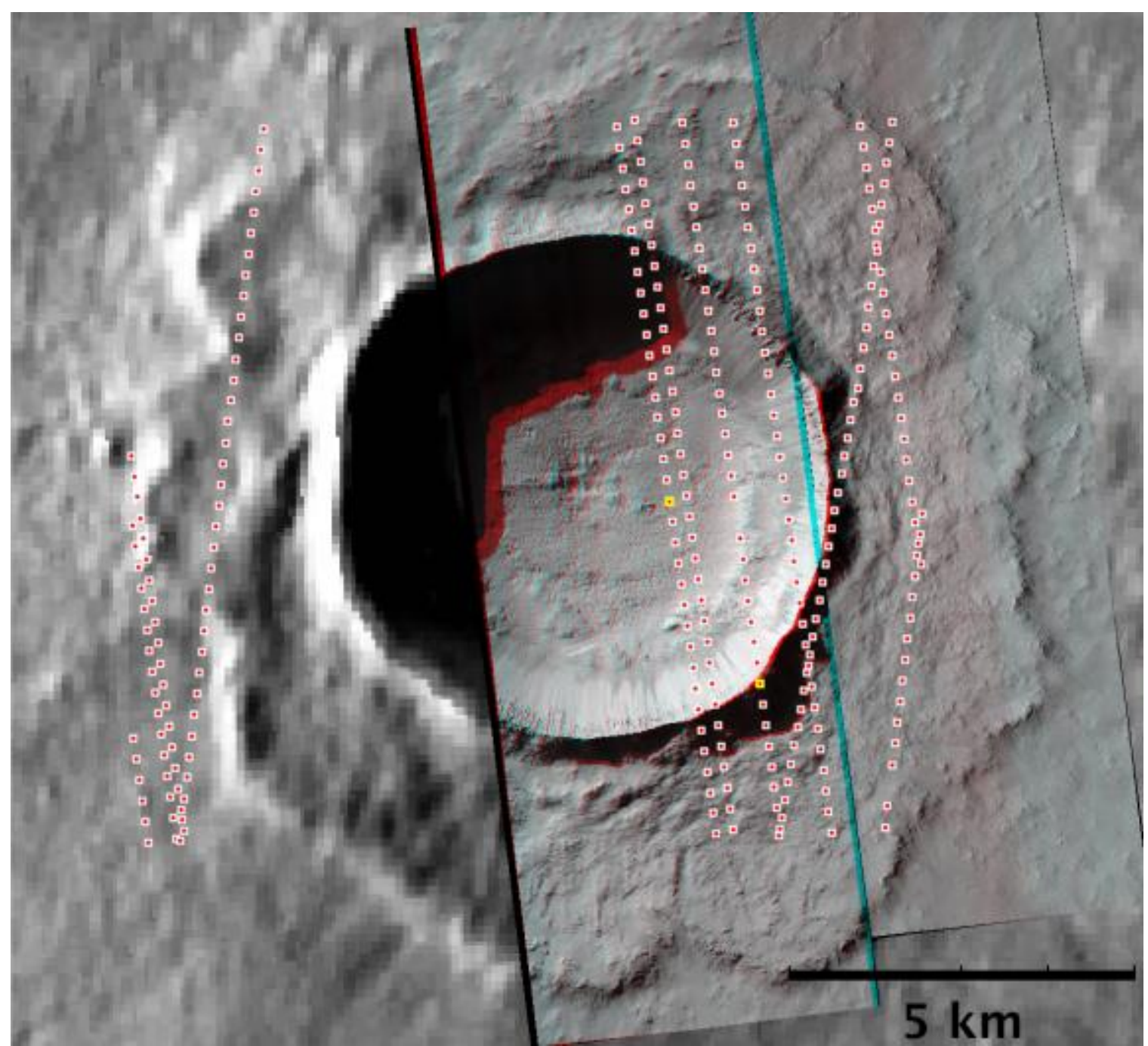

Figure S1. Example of the use of a set of HiRISE anaglyphs to evaluate the sparse MOLA PEDR shot (red squares) coverage of Resen Crater. The lowest floor and highest rim elevations are represented by the squares highlighted in yellow. Despite the sparse coverage by MOLA PEDR shots (less than 50\% coverage of the crater rim/interior), the lowest floor (outside of an incipient central pit) and the highest rim elevations are in fact captured by the dataset. Image credits: NASA/JPL-CALTECH/GSFC/ASU, NASA/JPLCALTECH/University of Arizona and NASA/JPL-CALTECH/ASU. 


\section{References}

Anderson, T.W., A, D.D., 1954. A Test of Goodness of Fit. Journal of the American Statistical Association 49, 765769. doi: $10.2307 / 2281537$

Bandfield, J.L., Edwards, C.S., Montgomery, D.R., Brand, B.D., 2013. The dual nature of the martian crust: Young lavas and old clastic materials. Icarus 222, 188-199. doi:10.1016/j.icarus.2012.10.023

Barlow, N.G., 2006. Impact craters in the northern hemisphere of Mars: Layered ejecta and central pit characteristics. Meteoritics \& Planetary Science 41, 1425-1436.

Boyce, J.M., Garbeil, H., 2007. Geometric relationships of pristine Martian complex impact craters, and their implications to Mars geologic history. Geophys. Res. Lett. 34, n/a-n/a. doi:10.1029/2007GL029731

Boyce, J.M., Mouginis-Mark, P., Garbeil, H., 2005. Ancient oceans in the northern lowlands of Mars: Evidence from impact crater depth/diameter relationships. J. Geophys. Res. 110, E03008. doi:10.1029/2004JE002328

Boyce, J.M., Mouginis-Mark, P., Garbeil, H., Tornabene, L.L., 2006. Deep impact craters in the Isidis and southwestern Utopia Planitia regions of Mars: High target material strength as a possible cause. Geophys. Res. Lett. 33, L06202. doi:10.1029/2005GL024462

Boyce, J.M., Wilson, L., Mouginis-Mark, P.J., Hamilton, C.W., Tornabene, L.L., 2012. Origin of small pits in martian impact craters. Icarus 221, 262-275. doi:10.1016/j.icarus.2012.07.027

Caudill, C.M., Tornabene, L.L., McEwen, A.S., Byrne, S., Ojha, L., Mattson, S., 2012. Layered MegaBlocks in the central uplifts of impact craters. Icarus 221, 710-720. doi:10.1016/j.icarus.2012.08.033

Christensen, P.R., Engle, E., Anwar, S., Dickenshied, S., Noss, D., Gorelick, N., Weiss-Malik, M., 2009. JMARS - A Planetary GIS, Presented at the American Geophysical Union 44.

Christensen, P.R., Jakosky, B.M., Kieffer, H.H., Malin, M.C., McSween, H.Y.J., Nealson, K., Mehall, G.L., Silverman, S.H., Ferry, S., Caplinger, M., Ravine, M., 2004. The Thermal Emission Imaging System (THEMIS) for the Mars 2001 Odyssey Mission. Space Sci Rev 110, 85-130. doi:10.1023/B:SPAC.0000021008.16305.94

Denevi, B.W., Blewett, D.T., Buczkowski, D.L., Capaccioni, F., Capria, M.T., De Sanctis, M.C., Garry, W.B., Gaskell, R.W., Le Corre, L., Li, J.Y., Marchi, S., McCoy, T.J., Nathues, A., O'Brien, D.P., Petro, N.E., Pieters, C.M., Preusker, F., Raymond, C.A., Reddy, V., Russell, C.T., Schenk, P., Scully, J.E.C., Sunshine, J.M., Tosi, F., Williams, D.A., Wyrick, D., 2012. Pitted Terrain on Vesta and Implications for the Presence of Volatiles. Science 338, 246-249. doi:10.1126/science.1225374

Edwards, C.S., Nowicki, K.J., Christensen, P.R., Hill, J., Gorelick, N., Murray, K., 2011. Mosaicking of global planetary image datasets: 1 . Techniques and data processing for Thermal Emission Imaging System (THEMIS) multi-spectral data. J. Geophys. Res. 116, E10008. doi:10.1029/2010JE003755

Garvin, J.B., Sakimoto, S.E.H., Frawley, J.J., 2003. Craters on Mars: Global Geometric Properties from Gridded MOLA Topography, Presented at the Sixth International Conference on Mars, Abstract \#3277.

Greeley, R., Guest, J., 1987. Geologic map of the eastern equatorial region of Mars USGS Miscellaneous Investigations Series Map I-1802-B, Scale 1:15,000,000.

Grieve, R., Dence, M.R., Robertson, P.B., 1977. Cratering processes-As interpreted from the occurrence of impact melts. In Impact and explosion cratering: Planetary and terrestrial implications (pp. 791-814).

Grotzinger, J.P., Sumner, D.Y., Kah, L.C., Stack, K., Gupta, S., Edgar, L., Rubin, D., Lewis, K., Schieber, J., Mangold, N., Milliken, R., Conrad, P.G., DesMarais, D., Farmer, J., Siebach, K., Calef, F., Hurowitz, J., McLennan, S.M., et al., 2014. A Habitable Fluvio-Lacustrine Environment at Yellowknife Bay, Gale Crater, Mars. Science 343, 1242777. doi:10.1126/science. 1242777

Hawke, B.R., Head, J.W., 1977. Impact melt on lunar crater rims. In Impact and explosion cratering: Planetary and terrestrial implications (pp. 815-841).

Hopkins, R.T., Collins, G.S., Osinski, G.R., Silber, E.A., 2015. Modelling the Effect of Material Anisotropy on Impacts into Layered Targets. Bridging the Gap III: Impact Cratering In Nature 1861, Abstract \#1092.

Jaumann, R., Neukum, G., Behnke, T., Duxbury, T.C., Eichentopf, K., Flohrer, J., Gasselt, S.V., Giese, B., Gwinner, K., Hauber, E., Hoffmann, H., Hoffmeister, A., Köhler, U., Matz, K.D., McCord, T.B., Mertens, V., Oberst, J., Pischel, R., Reiss, D., Ress, E., Roatsch, T., Saiger, P., Scholten, F., Schwarz, G., Stephan, K., Wählisch, M., 2007. The high-resolution stereo camera (HRSC) experiment on Mars Express: Instrument aspects and experiment conduct from interplanetary cruise through the nominal mission. Planetary and Space Science 55, 928-952. doi:10.1016/j.pss.2006.12.003

Johnsson, A., Reiss, D., Hauber, E., Hiesinger, H., Zanetti, M., 2014. Evidence for very recent melt-water and debris flow activity in gullies in a young mid-latitude crater on Mars. Icarus 235, 37-54. doi:10.1016/j.icarus.2014.03.005

Kalynn, J., Johnson, C.L., Osinski, G.R., Barnouin, O., 2013. Topographic characterization of lunar complex craters 40, 38-42. doi:10.1029/2012GL053608

Kolmogorov, A.N., 1933. Sulla determinazione empirica di una legge di distribuzione. Giorn. Ist. Ital. Attuari. doi:10.2307/3315325/full

Malin, M.C., Bell, J.F., III, Cantor, B.A., Caplinger, M.A., Calvin, W.M., Clancy, R.T., Edgett, K.S., Edwards, L., Haberle, R.M., James, P.B., Lee, S.W., Ravine, M.A., Thomas, P.C., Wolff, M.J., 2007. Context Camera Investigation on board the Mars Reconnaissance Orbiter. J. Geophys. Res. 112, E05S04. 
doi:10.1029/2006JE002808

McCoy, T.J., Sims, M., Schmidt, M.E., Edwards, L., Tornabene, L.L., Crumpler, L.S., Cohen, B.A., Soderblom, L.A., Blaney, D.L., Squyres, S.W., Arvidson, R.E., Rice, J.W., Jr., Tréguier, E., d'Uston, C., Grant, J.A., McSween, H.Y., Jr., Golombek, M.P., Haldemann, A.F.C., de Souza, P.A., Jr., 2008. Structure, stratigraphy, and origin of Husband Hill, Columbia Hills, Gusev Crater, Mars. J. Geophys. Res. 113, E06S03. doi:10.1029/2007JE003041

McEwen, A.S., Hansen, C.J., Delamere, W.A., Eliason, E.M., Herkenhoff, K.E., Keszthelyi, L., Gulick, V.C., Kirk, R.L., Mellon, M.T., Grant, J.A., Thomas, N., Weitz, C.M., Squyres, S.W., Bridges, N.T., Murchie, S.L., Seelos, F., Seelos, K., Okubo, C.H., Milazzo, M.P., Tornabene, L.L., Jaeger, W.L., Byrne, S., Russell, P.S., Griffes, J.L., Martinez-Alonso, S., Davatzes, A., Chuang, F.C., Thomson, B.J., Fishbaugh, K.E., Dundas, C.M., Kolb, K.J., Banks, M.E., Wray, J.J., 2007a. A Closer Look at Water-Related Geologic Activity on Mars. Science 317, 17061709. doi:10.1126/science. 1143987

McEwen, A.S., Eliason, E.M., Bergstrom, J.W., Bridges, N.T., Hansen, C.J., Delamere, W.A., Grant, J.A., Gulick, V.C., Herkenhoff, K.E., Keszthelyi, L., Kirk, R.L., Mellon, M.T., Squyres, S.W., Thomas, N., Weitz, C.M., 2007b. Mars Reconnaissance Orbiter's High Resolution Imaging Science Experiment (HiRISE). J. Geophys. Res. 112, E05S02. doi:10.1029/2005JE002605

McEwen, A.S., Tornabene, L., Grant, J., Wray, J., Mustard, J., 2008. Noachian Megabreccia on Mars. American Geophysical Union 43.

Melosh, H.J., 1989. Impact cratering: A geologic process. Research supported by NASA. New York, Oxford University Press (Oxford Monographs on Geology and Geophysics, No. 11), 1989, 253 p. 1.

Mouginis-Mark, P.J., 2015. Cratering on Mars with almost no atmosphere or volatiles: Pangboche crater. Meteoritics \& Planetary Science 50, 51-62. doi:10.1111/maps.12400

Mouginis-Mark, P.J., Boyce, J., Sharpton, V.L., Garbeil, H., 2017. Determination of Mars crater geometric data: Insights from high-resolution digital elevation models. Meteoritics \&amp; Planetary Science 278, 533. doi:10.1111/maps.12895

Mouginis-Mark, P.J., Boyce, J.M., 2012. Chemie der Erde. Chemie der Erde - Geochemistry 72, 1-23. doi:10.1016/j.chemer.2011.12.001

Mouginis-Mark, P.J., Garbeil, H., 2007. Crater geometry and ejecta thickness of the Martian impact crater Tooting 42, 1615-1625. doi:10.1111/j.1945-5100.2007.tb00594.x

Neukum, G., Jaumann, R., 2004. HRSC: The high resolution stereo camera of Mars Express. Mars Express: The Scientific Payload.

Osinski, G.R., Lee, P., Spray, J.G., Parnell, J., Lim, D., Bunch, T.E., Cockell, C.S., Glass, B., 2005. Geological overview and cratering model for the Haughton impact structure, Devon Island, Canadian High Arctic. Meteoritics \& Planetary Science 40, 1759-1776. doi:10.1111/j.1945-5100.2005.tb00145.x

Pierazzo, E., Melosh, H.J., 2000. Understanding Oblique Impacts from Experiments, Observations, and Modeling. Annu. Rev. Earth Planet. Sci. 28, 141-167. doi:10.1146/annurev.earth.28.1.141

Pike, R.J., 1980a. Terrain Dependence of Crater Morphology on Mars: both yes and no. In Lunar and Planetary Science Conference 11, 885-887.

Pike, R.J., 1980b. Control of crater morphology by gravity and target type - Mars, earth, moon. In Lunar and Planetary Science Conference 11, 2159-2189.

Pike, R.J., 1981. Target-Dependence of Crater Depth on the Moon. In Lunar and Planetary Science Conference 12, 845-847.

Pike, R.J., Davis, P.A., 1984. Toward a Topographic Model of Martian Craters from Photoclinometry, In Lunar and Planetary Science Conference 15, 645-646.

Quantin, C., Flahaut, J., Clenet, H., Allemand, P., Thomas, P., 2012. Composition and structures of the subsurface in the vicinity of Valles Marineris as revealed by central uplifts of impact craters. Icarus 221, 436-452. doi:10.1016/j.icarus.2012.07.031

Robbins, S.J., Hynek, B.M., 2013. Utility of laser altimeter and stereoscopic terrain models: Application to Martian craters. Planetary and Space Science 86, 57-65. doi:10.1016/j.pss.2013.06.019

Robbins, S.J., Hynek, B.M., 2012a. A new global database of Mars impact craters $\geq 1 \mathrm{~km}: 2$. Global crater properties and regional variations of the simple-to-complex transition diameter. J. Geophys. Res. 117, E06001. doi:10.1029/2011JE003967

Robbins, S.J., Hynek, B.M., 2012b. A new global database of Mars impact craters $\geq 1 \mathrm{~km}: 1$. Database creation, properties, and parameters. J. Geophys. Res. 117, E05004. doi:10.1029/2011JE003966

Robbins, S.J., Watters, W.A., Chappelow, J.E., Bray, V.J., Daubar, I.J., Craddock, R.A., Beyer, R.A., Landis, M., Ostrach, L.R., Tornabene, L.L., Riggs, J., Weaver, B.P., 2017. How Impact Crater "Depth" Is Determined, and a Review of Solar System Impact Crater Depths. Meteoritics \& Planetary Science - in press.

Scott, D.H., Tanaka, K.L., Geology, P., 1986. Geologic Map of the Western Equatorial Region of Mars. United States Geological Survey Miscellaneous Investigations Series, Map I-1802-A, Scale 1:15,000,000.

Senft, L.E., Stewart, S.T., 2008. Impact crater formation in icy layered terrains on Mars. Meteoritics \&amp; Planetary Science 43, 1993-2013. doi:10.1111/j.1945-5100.2008.tb00657.x

Senft, L.E., Stewart, S.T., 2011. Modeling the morphological diversity of impact craters on icy satellites. Icarus 214 , 67-81. doi:10.1016/j.icarus.2011.04.015 
Sizemore, H.G., Platz, T., Schorghofer, N., Crown, D.A., Prettyman, T.H., De Sanctis, M.C., Buczkowski, D.L., Hughson, K.H.G., Marchi, S., Mest, S.C., Williams, D.A., Schenk, P.M., Bland, M.T., Schmidt, B.E., Chilton, H.T., Russell, C.T., Raymond, C.A., 2017. Ceres' Pitted Terrains: Morphological Context and Implications for Ground Ice. In Lunar and Planetary Science Conference 48, Abstract \# 2033.

Smirnov, N.V., 1939. On the estimation of the discrepancy between empirical curves of distribution for two independent samples. Bull. Math. Univ. Moscou. 2, 3-16.

Smith, D.E., Zuber, M.T., Frey, H.V., Garvin, J.B., Head, J.W., Muhleman, D.O., Pettengill, G.H., Phillips, R.J., Solomon, S.C., Zwally, H.J., Banerdt, W.B., Duxbury, T.C., Golombek, M.P., Lemoine, F.G., Neumann, G.A., Rowlands, D.D., Aharonson, O., Ford, P.G., Ivanov, AB, Johnson, C.L., McGovern, P.J., Abshire, J.B., Afzal, R.S., Sun, X.L., 2001. Mars Orbiter Laser Altimeter: Experiment summary after the first year of global mapping of Mars. J. Geophys. Res. 106, 23689-23722.

Stepinski, T.F., Mendenhall, M.P., Bue, B.D., 2009. Machine cataloging of impact craters on Mars. Icarus 203, $77-87$. doi:10.1016/j.icarus.2009.04.026

Stewart, S.T., Valiant, G.J., 2006. Martian subsurface properties and crater formation processes inferred from fresh impact crater geometries. Meteoritics \& Planetary Science 41, 1509-1537. doi:10.1111/j.19455100.2006.tb00433.x

Susorney, H.C.M., Barnouin, O.S., Ernst, C.M., Johnson, C.L., 2016. Morphometry of impact craters on Mercury from MESSENGER altimetry and imaging. Icarus 271, 180-193. doi:10.1016/j.icarus.2016.01.022

Tanaka, K.L., Robbins, S.J., Fortezzo, C.M., Skinner, J.A.J., Hare, T.M., 2014. The digital global geologic map of Mars: Chronostratigraphic ages, topographic and crater morphologic characteristics, and updated resurfacing history. Planetary and Space Science 95, 11-24. doi:10.1016/j.pss.2013.03.006

Tornabene, L.L., McEwen, A.S., Osinski, G.R., Boyce, J.M., Williams, R., Wray, J.J., Grant, J.A., 2007. Impact melting and the role of subsurface volatiles: Implications for the formation of valley networks and phyllosilicaterich lithologies on early Mars, Presented at the Seventh International Mars Conference, Abstract\# 3288.

Tornabene, L.L., Moersch, J.E., McSween, H.Y., Jr, McEwen, A.S., Piatek, J.L., Milam, K.A., Christensen, P.R., 2006. Identification of large $(2-10 \mathrm{~km})$ rayed craters on Mars in THEMIS thermal infrared images: Implications for possible Martian meteorite source regions. J. Geophys. Res. 111, E10006. doi:10.1029/2005JE002600

Tornabene, L.L., Osinski, G.R., McEwen, A.S., Boyce, J.M., Bray, V.J., Caudill, C.M., Grant, J.A., Hamilton, C.W., Mattson, S., Mouginis-Mark, P.J., 2012. Widespread crater-related pitted materials on Mars: Further evidence for the role of target volatiles during the impact process. Icarus 220, 348-368. doi:10.1016/j.icarus.2012.05.022

Watters, W.A., Geiger, L.M., Fendrock, M., Gibson, R., 2015. Morphometry of small recent impact craters on Mars: Size and terrain dependence, short-term modification. J. Geophys. Res. Planets 120, 226-254. doi:10.1002/2014JE004630

Whitehead, J., Grieve, R., Spray, J.G., 2010. The effects of crater degradation and target differences on the morphologies of Martian complex craters. GSA Spec. Paper 465, 67-80. doi:10.1130/2010.2465(05) 